\title{
Revisión de los testimonios y documentos sobre el lugar del hallazgo de la Dama de Elche. La "fita" de Pedro Ibarra y la recreación de Ramos Folqués
}

\section{Review of the testimonies and documents about the place of the find of the Lady of Elche. The milestone of Pedro Ibarra and the recreation of Ramos Folqués}

\author{
Ana M. ${ }^{a}$ Ronda Femenia ${ }^{1}$ \\ Fundación Arqueológica L'Alcúdia. Universidad de Alicante
}

\section{RESUMEN}

El descubrimiento de la Dama de Elche en el yacimiento de La Alcudia ha cumplido 120 años el pasado 4 de agosto de 2017. La historia sobre el hallazgo ha llegado hasta nosotros por un protagonista coetáneo al momento: el archivero ilicitano Pedro Ibarra Ruiz. El regreso de la escultura en 1941, motivado por un canje entre el gobierno francés del mariscal Pétain y Franco, disparó el interés por la célebre escultura ibérica y su historia. Alejandro Ramos Folqués, dueño y excavador del yacimiento de La Alcudia, presentó el relato de un nuevo y desconocido descubridor, que varió algunas partes del testimonio original de Pedro Ibarra. El análisis actualizado de los testimonios gráficos y documentales, nos han permitido sacar a la luz nuevas hipótesis sobre el contexto arqueológico en que debió aparecer la obra cumbre de la escultura ibérica.

\section{SUMMARY}

The discovery of the Lady of Elche in the site of La Alcudia has turned 120 years the last 4 of August, 2017. The story about the find has come down to us by a contemporary protagonist at that time: the Ilicitan archivist Pedro Ibarra Ruiz. The return of the sculpture in 1941, motivated by a swap between the French government of marshal Pétain and Franco, triggered interest in the famous Iberian sculpture and its history. Alejandro Ramos Folqués, owner and excavator of the site of La Alcudia, presented the story of a new and unknown discoverer, which varied some parts of the original testimony of Pedro Ibarra. The updated analysis of graphic and documentary evidences, has allowed us to bring to light new hypotheses about the archaeological context in which the masterpiece of Iberian sculpture should have appeared.

PALABRAS CLAVE: La Alcudia; busto de Elche; escultura ibérica; plano de situación; contexto arqueológico; datos documentales.

${ }^{1}$ ana.ronda@ua.es / ORCID iD: https://orcid.org/00000002-4761-9316
KEY WORDS: La Alcudia; bust of Elche; Iberian sculpture; situation map; archaeological context; documentary data.

CÓMO CITAR ESTE ARTÍCULO / CITATION: Ronda Femenia, A. M. a 2018: "Revisión de los testimonios y documentos sobre el lugar del hallazgo de la Dama de Elche. La "fita' de Pedro Ibarra y la recreación de Ramos Folqués". Archivo Español de Arqueología 91: 279-303. https://doi. org/10.3989/aespa.091.018.014

Los primeros vestigios que surgieron sobre la cultura ibérica fueron las esculturas del Cerro de los Santos aparecidas en las excavaciones de los padres Escolapios de Yecla en 1871, evidencias iniciales de ese raro arte que semejaba mediterráneo, pero del que se desconocía todo. Cientos de fragmentos de esculturas fueron comprados en grandes lotes por el Museo Arqueológico Nacional entre 1871 y 1872, teniendo éstas, a través de moldes producto de vaciado, su presentación oficial al mundo científico en la Exposición Universal de Viena de 1873 y la de París de 1878. Pero al poco tiempo, los naturales debates y opiniones sobre el arte ibérico se vieron ensombrecidos por el turbio asunto de las falsificaciones de Vicente J. Amat, más conocido como "el relojero de Yecla", cuestión que dirimieron con diferentes estudios L. Heuzey en 1891, E. Hübner en 1893 y finalmente J. R. Mélida, quién a lo largo de 1903 y 1905, zanjó la cuestión definitivamente (Chapa y González 2013: 116-128).

En aquel ambiente científico de desconfianza ante este arte nuevo, es donde surge casualmente el busto de Elche el miércoles 4 de agosto de 1897 durante las tareas de laboreo y adecuación del pedregoso solar de La Alcudia en finca agrícola. Corrían tiempos 
difíciles en el solar patrio, "He recibido la infausta noticia del haber sido asesinado D. Antonio Cánovas del Castillo", es el testimonio intercalado por Pedro Ibarra entre sus notas sobre el hallazgo (Ibarra Ruiz Efemérides $\mathrm{n}^{\circ} 122$ de 9 de agosto), luctuosa y preocupante noticia del día 8 que, junto a las que llegaban de las colonias, ensombreció la difusión de la noticia en prensa (García y Gómez 1997: 223; Rodríguez-Tajuelo 2016: 251). La propia historia de la escultura se entreteje con la de nuestro país en momentos críticos (Fig. 1). Su aparición e inmediata pérdida tan cercana a la crisis del 98, y el regreso de Francia en 1941 tras la guerra civil de la mano del régimen franquista, son episodios que hicieron de ella un mito, "ideal del alma de España" en palabras de Ricardo Olmos (1997a: 20).

Pero lo cierto es que el descubrimiento de la Dama de Elche cambió el rumbo de la incipiente historia de la cultura ibérica. La pieza, por su ambigüedad formal y estética, planteó nuevas preguntas y variadas respuestas que vinieron a enriquecer los planteamientos sobre el arte ibérico, poniéndolo en relación con el arte griego, el etrusco y el fenicio-púnico, para incluir definitivamente a la Península Ibérica en el círculo de la amalgama de las culturas mediterráneas antes de Roma. Desde el mismo día en que apareció, los escritos periodísticos, los estudios y los libros sobre la Dama conforman un largo y extenso corpus con puntos de vista caleidoscópicos, incluso alguno llegó a sembrar la duda sobre su autenticidad (Moffit 1996 y 2005). Esta infundada sospecha fue rebatida de manera contundente por autores como J. M. Blázquez (1995; 2004-2005; 2006 y 2013), R. Olmos y T. Tortosa (1996), L. Abad (1997), G. Nicolini (1997) o Villarías-Robles et alii (1997: 241-248), a cuyos argumentos también se han sumado los análisis de la pieza que ratifican la antigüedad de sus pigmentos (Rodero y Rovira 1997; Gómez et alii 2008) y la confirmación de que contuvo en su hueco dorsal los restos óseos de una cremación (Luxán et alii 2011).

De este modo, cuando parece que todo está dicho sobre la Dama, que ha sido y es "objeto de mil palabras" (Olmos 1997b: 83), otra mirada puede entrever algún aspecto que, por conocido, se había pasado por alto. Este es el caso que nos ocupa, ya que los estudios sobre la figura del arqueólogo ilicitano A. Ramos Folqués en mi reciente tesis doctoral (Ronda 2016 y 2018) me han llevado — sin pretenderlo- a descubrir ciertos ítems harto asumidos que necesitaban revisarse de nuevo y que, quizás, puedan dar respuesta a preguntas concretas sobre el momento del hallazgo formuladas por los especialistas a lo largo del tiempo (Nicolini 1974: 64; Olmos y Tortosa 1997: 69-79; Ramos Fernández 1997: 75-90).

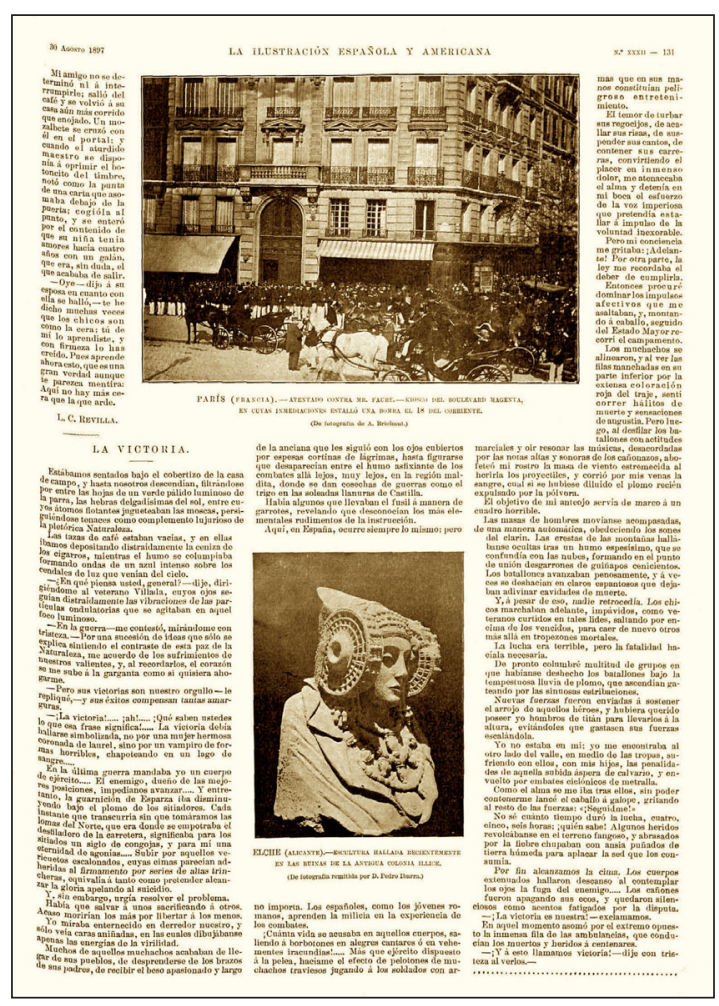

Figura 1. Fotografía de la Dama hecha por Ibarra Ruiz. Publicada en la Ilustración Española y Americana el 30 de agosto de 1897 (Biblioteca Nacional).

\section{LOS TESTIMONIOS DEL HALLAZGO}

\section{¿Dónde apareció? El ReCONOCIMIEnto DE DOS EMPLAZAMIENTOS}

$\mathrm{El}$ aspecto fundamental del presente estudio trata sobre el punto exacto de la ubicación del hallazgo en el yacimiento que, a pesar de lo consabido, nos ha llevado a reconocer dos localizaciones distintas a lo largo del tiempo, con una diferencia aproximada de $50 \mathrm{~m}$ entre las mismas. Para el análisis han sido básicas las dos narraciones fundamentales sobre el hallazgo: la redactada por Pedro Ibarra en 1897 y la escrita por Alejandro Ramos Folqués en 1944, así como el legado gráfico de ambos.

El estudio de la documentación original del que fuera propietario y excavador de La Alcudia durante los casi tres últimos cuartos del siglo xx, nos ha acercado a la realidad física del yacimiento años después de la aparición de la Dama. Hemos comprobado que en el lenguaje descriptivo utilizado por Alejandro Ramos, el punto del hallazgo fue hasta 1935 un referente visual y topográfico, materializado en un mojón, o fita según Ibarra Ruiz (Fig. 2), que se trata en realidad 


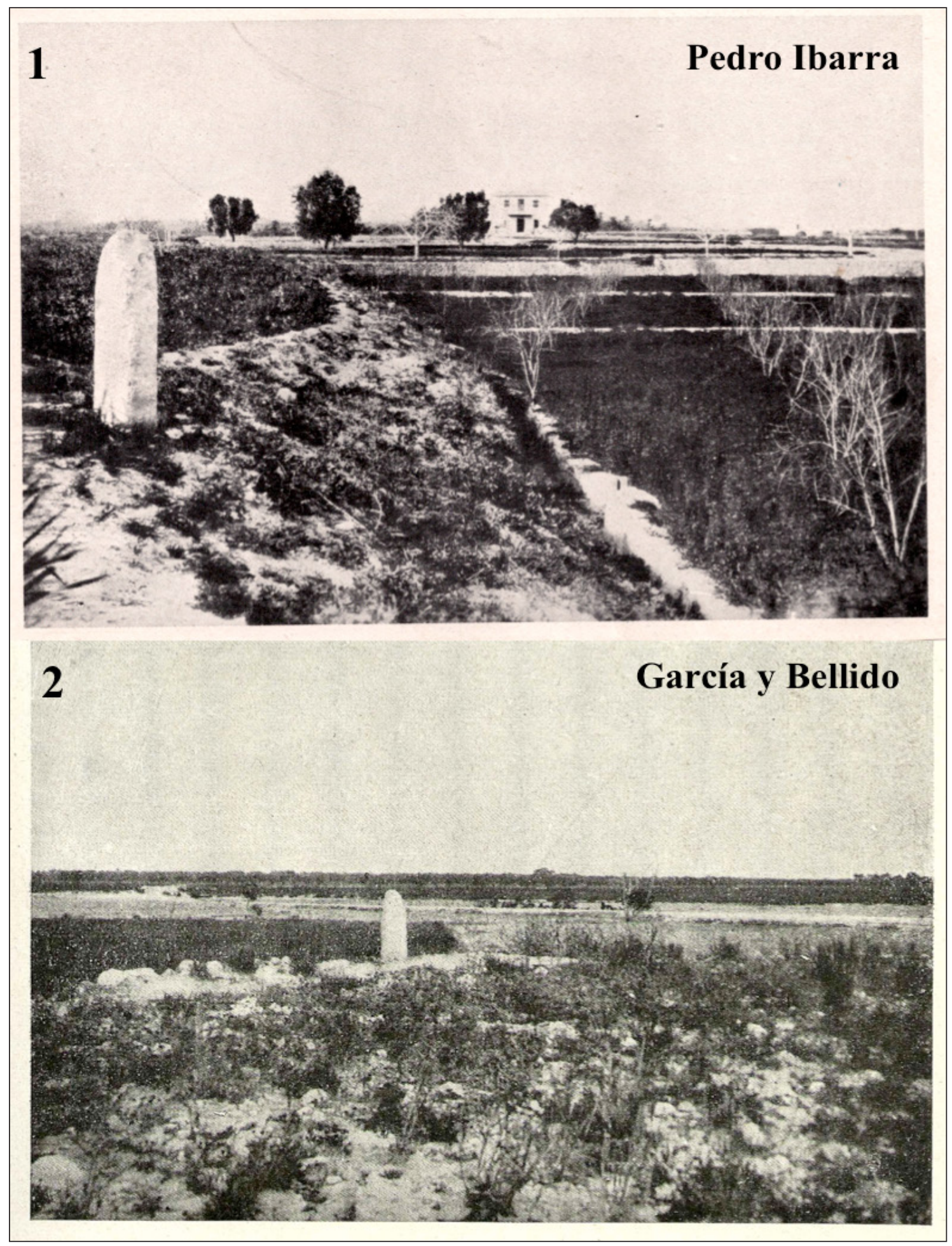

Figura 2. 1. Fotografía de Pedro Ibarra del cipo conmemorativo situado el 12 de junio de 1898 en el lugar del hallazgo. 2. Fotografía poco conocida del cipo o mojón desde el interior de la loma; publicada como fig. 5 en el libro de 1943 de García y Bellido, de la que se desconoce su autoría. 


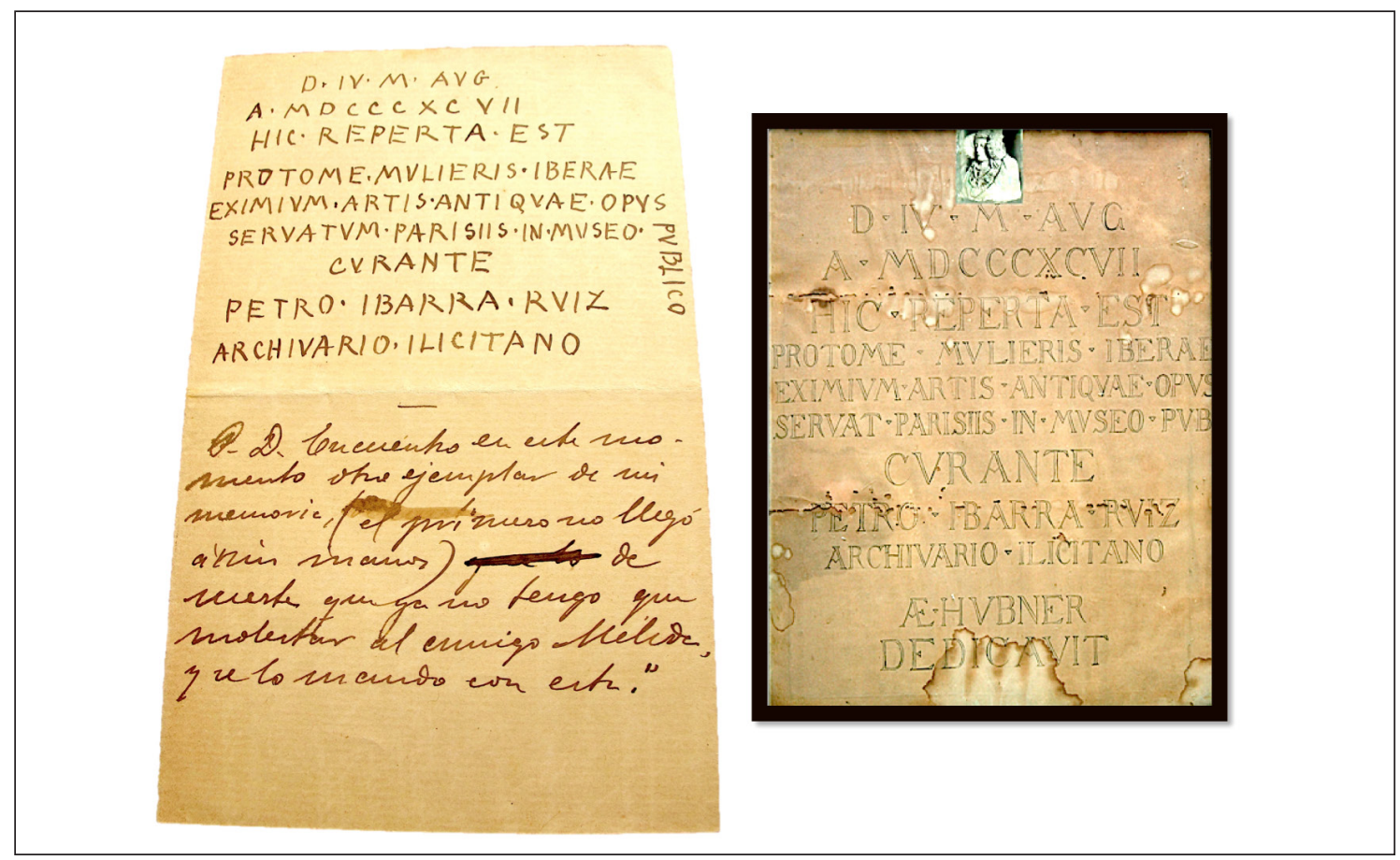

Figura 3. Documento original del AHME y cuadro de la Fundación Arqueológica L'Alcúdia, ambos de Pedro Ibarra Ruiz (fotografías propias). El cuadro actualmente está depositado en el Archivo General de la Universidad de Alicante.

del fuste de una columna de piedra caliza que se había recuperado en las faenas efectuadas en el bancal del hallazgo de la Dama entre octubre y diciembre de 1897. García y Bellido comenta acerca de esas "indagaciones" sobre el terreno que se realizaron con posterioridad al descubrimiento, el hallazgo de "un trozo de fuste de columna de 1'20 m de longitud y gran cantidad de piedras de construcción", cita que recoge a su vez de Mélida, y éste de Hübner (García y Bellido 1943: 16), con referencias a los materiales hallados en el entorno y que analizaremos en detalle más adelante.

\section{I898. LA “FITA” DE PEDRo IbARRA}

La fecha de colocación del mojón o cipo conmemorativo, nos la relata el propio Ibarra Ruiz diez meses después de la aparición de la Dama en su Efemérides $\mathrm{n}^{\circ} 147$ de 13 de junio de 1898 (AHME) ${ }^{2}$, la que transcribimos por su interés:

"Esta tarde he recibido la visita de Mr. Paris y de D. Pascual Serrano de Bonete./ Hemos estado en la Alcudia, donde están cavando para sembrar alfalfa, al

\footnotetext{
${ }^{2}$ Acrónimo del Archivo Histórico Municipal de Elche.
}

norte, lindando con los olivares de Rojas, donde han salido, revueltos en la tierra muchos tiestos y un cráneo humano. Luego visitamos el punto en donde fue hallado el célebre busto y habiendo invitado al capataz Galiano, para que plantara una fita que perpetúe la memoria del sitio donde fué [sic.] descubierta la hermosa escultura, así lo hemos hecho, colocando sobre el margen, recientemente formado con gruesa piedras y tierra apisonada, frente al punto del hallazgo unos diez metros à [sic.] poniente, el trozo de columna que se encontró en el ángulo de más al norte, hasta que yo prepare una inscripción adecuada".

Su pretensión era grabar — a modo de epígrafe antiguo y sobre la columna - la leyenda que el hispanista alemán Emil Hübner le había dedicado por petición expresa suya, aunque de ella solo han quedado testimonios escritos, como el documento suelto, copia de la carta original del Archivo Histórico Municipal de Elche: "Berlín 29 Nov. 1898 [...] junto le mando el texto para la inscripción à ponerse en el lugar del hallazgo, mire que no se engañe el picapedrero", y también el cuadro que Ibarra confeccionó para sí, pues la inscripción nunca se materializó ${ }^{3}$ (Fig. 3). El

\footnotetext{
${ }^{3}$ El texto, según la traducción que amablemente ha hecho el profesor Lorenzo Abad, vendría a decir: "El día 4 de agosto /
} 
porqué de esta intrahistoria lo cuenta Nicolau Primitiu Gómez Serrano al que Pedro Ibarra confesó —en una entrevista de 1925- que en el texto original, Hübner había escrito ourante en lugar de curante, error tipográfico que hacía parecer al erudito "culpable" de la venta del busto (Gómez 1948: 66). Quizás ese sinsabor le llevó a dejar sin grabar la piedra y a subsanar el error en el cuadro que enmarcó con la fotografía que el mismo hiciera de la Dama presidiéndolo.

La imagen más conocida del mojón es la que publicó Ibarra Ruiz (Fig. 2.1) acompañada de la siguiente descripción del punto concreto:

"Nos hemos de dirigir hacia el sur si hemos de visitar el punto en donde se ha verificado el famoso hallazgo objeto de este estudio. En la última estribación de la loma, en el ángulo que forma el terreno levantado al sudeste, y a unos 50 metros antes de llegar al sur, en el talud mismo del margen que limita las tierras altas, se presentó a las miradas atónitas de los cavadores, la escultura que hoy todos admiramos" (Ibarra Ruiz 1926: 195).

El complemento a estos datos es el gran "Plano General de la Alcúdia solar de la antigua Illici, por P. Ibarra y Ruiz", cuya ejecución está fechada en 1890 y contiene los cuatro hitos de los que fue testigo sobre el terreno: las Thermas excavadas por la "Sociedad La Alcudia" y dirigidas por él mismo en 1890, el punto de la Dama donde situó el mojón en 1898, y también las excavaciones de E. Albertini en 1905 que incluían el sondeo II y, por último, la planta de la basílica, todo a escala 1:500 (Fig. 4).

El relato de la Dama, y sus aportaciones sobre el busto, fueron recopilados por Ibarra Ruiz en el capítulo VI de su obra Elche, materiales para su historia, con el título "Noticia de su descubrimiento. Descripción de su imagen. Controversia a la que dio lugar su estilo y conclusiones" (Ibarra Ruiz 1926: 190-213). La tardía fecha de publicación del libro le sirvió para reafirmarse en sus posiciones sobre la escultura y responder a título personal a todas esas "controversias" que el estudio de la pieza había suscitado a otros investigadores a lo largo de los años desde el descubrimiento de la misma. Pero además existen otros documentos suyos originales, como son las siete cuartillas manuscritas que envió al periódico local "Nueva Illice" el 5 de agosto de 1917, y que reproducen casi íntegramente el primer testimonio

de 1897 / se descubrió aquí / el busto de una mujer ibera / obra extraordinaria del arte antiguo / que se conserva en París en un museo público / Aemilius Hübner / lo dedicó / a Pedro Ibarra Ruiz / archivero ilicitano / que se ocupó de ella". que escribiera el 14 de agosto de 1897, ahora con el subtítulo "En el vigésimo aniversario de su hallazgo. Noticia tomada de mi diario" (AHME, legajo M3/n ${ }^{\circ}$ 29, r. 97). La transcripción de este documento de 1917 fue publicada por primera vez en el libro de 1997 "La Dama de Elche. Lecturas desde la diversidad" (Olmos y Tortosa 1997: 72-74) e incluyó el detalle o "viñeta" del perfil de la silueta de la Dama que encabeza el documento (Fig. 5). De idéntica naturaleza es otro original que se conserva en la Biblioteca Ramos, ref. «El busto de Elche», que "va encabezado por un tríptico fotográfico de la Dama, de frente y de mayor tamaño en el centro, de espaldas a la izquierda y de perfil a la derecha, con el pie «Hallazgo en Elche (Illici) 4 Agosto 1897»”, según transcripción literal de R. Ramos Fernández de su libro Documentos y reflexiones sobre una Dama (2003: 36-38, nota 55 y 57).

Ibarra extractó sus impresiones, quizás las más personales e inmediatas, en tres Efemérides: la no 121 de 4 de agosto "Hallazgo de un hermoso busto en La Alcudia", la no 123 de fecha 18 "Venta del busto!!!", y la última no 124 de 30 de agosto "¡Adiós al busto!". Los datos sobre el hallazgo los escribe en la ${ }^{\circ} 121$ :

"Grandioso hallazgo en la Alcudia cavando al mediodía de la loma para arreglar unos bancalitos donde van á [sic.] plantarse granados, y a una distancia de 50 mts. al interior, de Este a Oeste, al pie mismo de la eminencia se ha encontrado una magnífica cabeza sacractil [sic.], de piedra franca, tamaño natural, en perfecto estado de conservación [...] la estoy estudiando" (AHME, legajo 3/nº 29, r. 155).

En ambas descripciones, la del libro y la de la Efemérides 121, coincide en que apareció en la vertiente SE, en el "ángulo levantado al sudeste" y "a mediodía de la loma", e informa de igual modo que la situación era en la parte baja del margen "al pie mismo de la eminencia" y "en el talud mismo del margen que limita las tierras altas", detalles que coinciden con el punto de su plano que rotula "busto 1897", y de dónde vemos que parte el sondeo II de E. Albertini que Ibarra Ruiz trasladó al plano (Fig. 4). Pero las distancias que da por escrito no son tan nítidas, ya que en un texto describe: "una distancia de $50 \mathrm{mts}$. al interior, de Este a Oeste", y en el otro: "a unos 50 metros antes de llegar al sur", referencias de tipo latitudinal en un caso y longitudinal en el otro, con el uso exclusivo de los puntos cardinales como referencia. Sin embargo en su plano lo sitúa de manera muy precisa en un punto de intersección entre cotas de nivel de distinta altura y a $35 \mathrm{~m}$ más al norte de la basílica, edificio que sí emplaza a $50 \mathrm{~m}$ del límite 


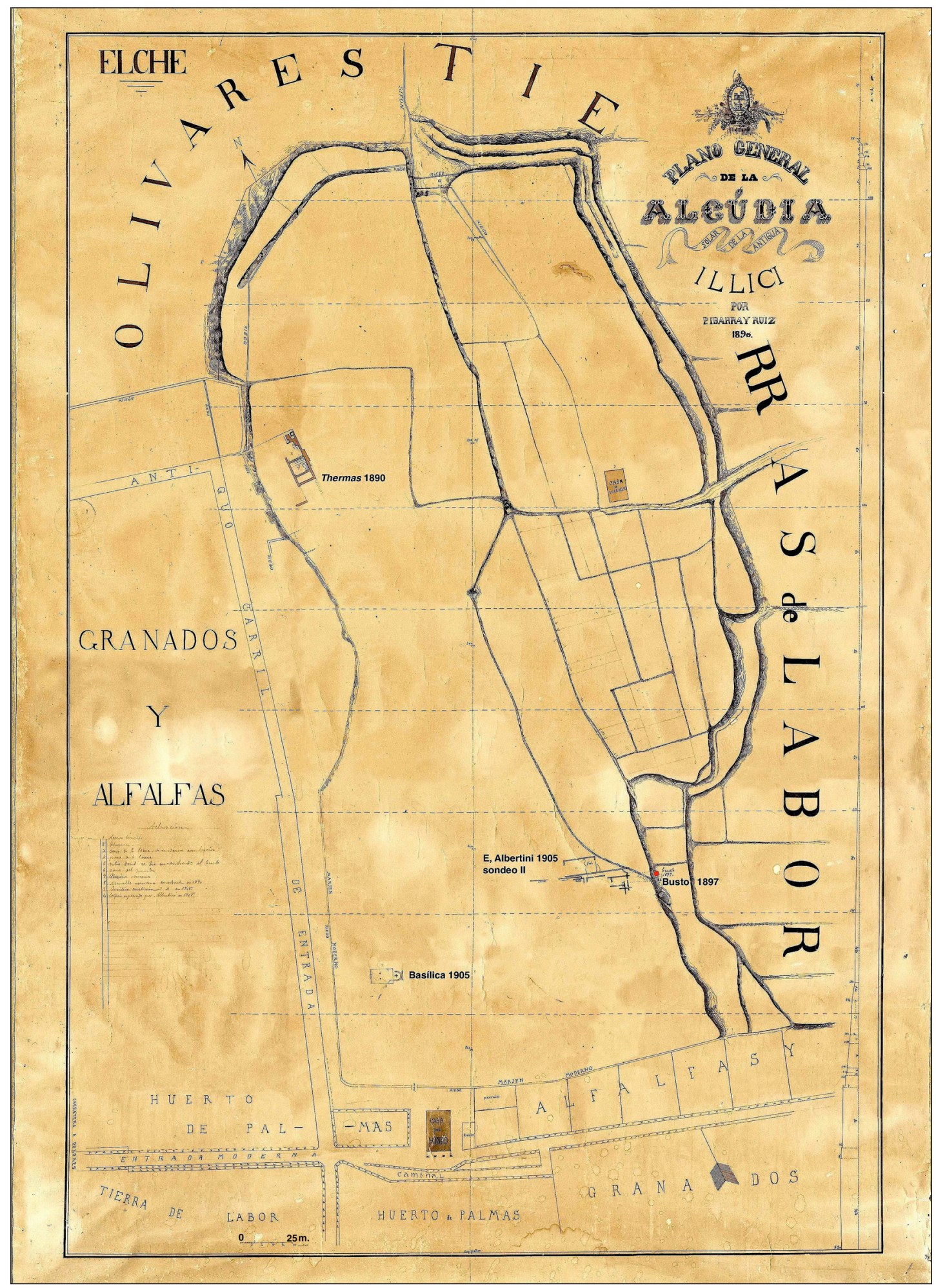

Figura 4. Plano de Ibarra Ruiz con las excavaciones en L'Alcúdia desde 1890 hasta 1905 (rotulado por nosotros para una mejor comprensión). Depositado en el Archivo General de la Universidad de Alicante. 


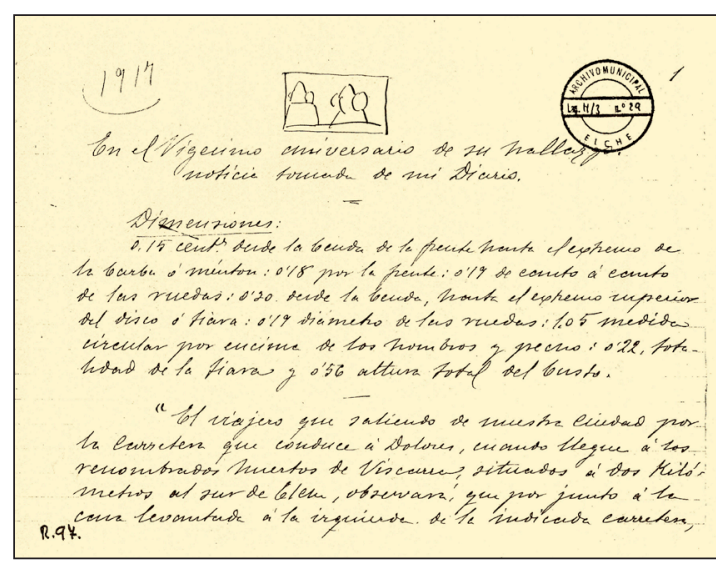

Figura 5. Folio 1 del relato del hallazgo escrito por Ibarra Ruiz, enviado por él mismo al periódico "Nueva Illice" en conmemoración del vigésimo aniversario del hallazgo (AHME).

sur de terreno en aquella época (Fig. 6). Queremos poner el énfasis en el gran valor testimonial del plano de Ibarra, un documento vivo al que sabemos que desde que lo creó en 1890 fue añadiéndole los hitos más significativos del solar a medida que iban sucediéndose en el tiempo. La situación del lugar de la Dama marcado por él mismo respecto a la basílica es lo que nos va a ofrecer una medición fidedigna, pues creemos que las reseñas a las distancias respecto a

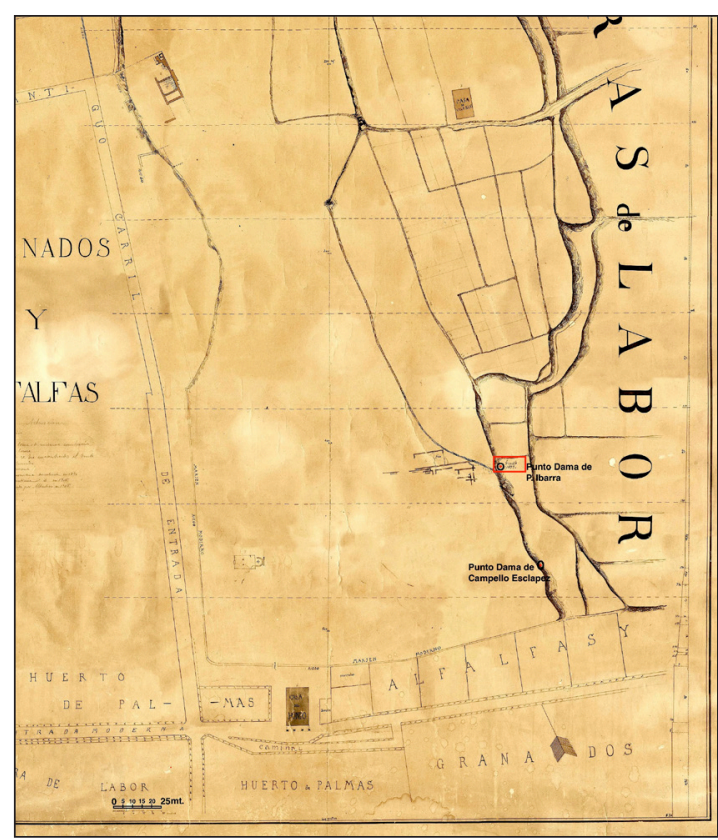

Figura 6. Detalle del plano a escala con el punto original de la "fita" de P. Ibarra y el cálculo aproximado de la distancia hasta el lugar que ocupa la recreación de Ramos Folqués, según las indicaciones de Campello Esclapez. los puntos cardinales quedan huecas ante la precisión planimétrica. Esta referencia será fundamental para explicar la otra parte de esta historia que analizaremos después, la que le contó el jornalero Manuel Campello Esclapez a Alejandro Ramos a inicios de la década de 1940.

\section{I897. QUi L'A TROUVÉ? El ELENCO DE PROTAGONISTAS DEL DESCUBRIMIENTO}

Un actor fundamental fue el comprador del busto, el anticuario galo Pierre Paris, cuyo testimonio nos guía para saber qué preguntas claves se hicieron en aquellos días de agosto en repetidas ocasiones al desvelarse el hallazgo. El primer interrogante de Paris a Ibarra al ver la foto de la Dama que este le mostraba a su llegada a Elche había sido: "D' où vient ce buste?", a lo que Perico ${ }^{4}$ sencillamente contestó "de la Alcudia”, y la inmediata fue "Qui l'a trouvé?", respondiendo: "El cuatro de agosto, un obrero de mi pariente Campello" (Paris 1907: 320; 1910: 80), simplemente.

Nos hemos de dirigir a la narración sobre "el descubrimiento" para encontrar un nombre y una herramienta, aquella que laceró la vieja piedra de la Dama al ser extraída de la tierra ${ }^{5}$. Creemos importante subrayar el hecho de la construcción del relato de Pedro Ibarra que, al no ser testigo directo del nacimiento, buscó un interlocutor al que hacerle las preguntas pertinentes — sin duda idénticas a las que hizo P. Paris: ¿dónde? y ¿quién?-, e insertó las respuestas del entrevistado en su redacción. Este testigo fue Antonio Galiano, el capataz de la finca del doctor Campello,

\footnotetext{
${ }^{4}$ El diminutivo - lo explica el propio Paris- era el modo afectuoso con que llamaban sus compatriotas al archivero (Paris 1907: 320). Se tiene igualmente constancia de que en ocasiones le añadían al mote "Perico l'antiu" por su afición desmedida a la historia y la arqueología (Verdú 2011: 9). Sería tras su fallecimiento cuando en Elche se le recordaría como Don Pedro Ibarra, el ilustre archivero que tanto había hecho por la historia local. Estas cuestiones que no parecen importantes, sin embargo dejan traslucir la incomprensión que este intelectual sufrió de la mayoría de sus coetáneos a lo largo de su vida.

${ }_{5}^{5} \mathrm{Al}$ respecto de la piedra con que fue hecha la Dama, Pedro Ibarra es el primero que habla de su origen ilicitano: "En Elche no tenemos mármoles a propósito; solo sí, piedra franca, arenisca, vulgar aquí, muy deleznable y porosa y sumamente sensible a la humedad. La piedra de la estatua es, según peritos, de la cantera de «Peligro», en el partido rural de este término denominado Ferriol." (Ibarra Ruiz 1926: 202). Este dato actualmente está plenamente confirmado —calcárea de la facies A del Mioceno medio, al parecer, la misma que la de la estatuaria ibérica de La Alcudia- por estudios geológicos y petrográficos del busto realizado por un equipo multidisciplinar de investigadores en las canteras de Ferriol (Gagnaison et alii 2007: 74; Moratalla et alii 2014).
} 
encargado de la vigilancia de las labores que allí se practicaban y que, hay que remarcar, tampoco estaba delante en el momento mismo de la aparición, sino que fue advertido por las jornaleros y que "dio orden para que excavaran cuidadosamente alrededor de la ignota piedra" (Ibarra Ruiz 1926:195). Las palabras que anota el archivero de boca del capataz sobre el descubridor son peyorativas para éste, pues dice literalmente: "Antonio Maciá, bracero que con otros estaba nivelando aquellas tierras, ha sido el que ha tocado con su herramienta la escultura", un problema más que un honor que su hija Dolores Maciá Torres narró así: "recuerda como su padre contaba que dio con su «picola» contra lo que parecía una roca y fue la Dama de Elche. Esto ocurría por la tarde, y el dueño de la finca, el doctor Campello, le pagó el jornal que fueron 7 reales, y allí terminó la jornada" ${ }^{6}$ (Payá 2007: 146).

El capataz realzó su protagonismo en las acciones del descubrimiento aclarando a Pedro Ibarra que:

"Hubiera esta perecido indudablemente, por creerla el cavador, una de tantas piedras como venían extrayéndose de aquel sitio, sin la oportuna presencia de Antonio Galiano Sánchez, quien advertido repetidas veces por el dueño de la propiedad para que escarbaran con cuidado el terreno, allí donde se presentara alguna piedra de cantería".

Es significativa la explicación de que hubiera perecido porque "el cavador", Antonio Maciá, la había confundido con una piedra, pues coincide con la versión de su hija. Pero además, se comprueba que en los recuerdos de Ibarra Ruiz el descubridor no es el obrero Maciá, sino Galiano, ya que guardó en su álbum personal una foto del capataz y su mujer — pegada arriba de dos fotografías de la Dama y a la izquierda de la noticia de la muerte de P. Paris, ocurrida en Madrid el 20 de octubre de 1931—, con el epígrafe "Antonio Galiano, que descubrió el busto" (Fig. 7), así como otras referencias a su persona como protagonista del suceso: "Tonico Galiano; este fue el que años después habría de encontrar el famoso busto" (AHME, libro 1, p. 363). De este modo Antonio Galiano, apodado "el borrasca", quedó como el actor principal que tomó las riendas del suceso, tanto en

\footnotetext{
${ }^{6}$ Los testimonios de la familia del jornalero Antonio Maciá Guilló, que era su nombre completo, son casi inexistentes. En una entrevista personal con su biznieto, el profesor de la Universidad de Alicante Francisco Maciá Pérez, nos habló de que en su familia el recuerdo era que el bisabuelo Antonio había estropeado la Dama con el pico, y de su miedo de que no volvieran a llamarle para ir a ganarse el jornal diario que llevar a casa; sin más.
}

su atenta vigilancia al extraerla como al conducirla hasta la casa del doctor en Elche:

"El asombro de todos los trabajadores es grande, cuando a la débil luz del mortecino crepúsculo de la tarde del 4 de agosto, admiraron el hermoso busto que a duras penas despojado de la tierra [...] fue cargado en el carrito del mencionado Galiano y conducido a Elche, a la presencia del dueño de la finca doctor don Manuel Campello y Antón” (Ibarra Ruiz 1926: 195).

En 1897 España aún no se había adaptado al horario referido al meridiano de Greenwich por lo que debemos entender que la hora de aparición sería alrededor de las siete de la tarde hora solar, pues en la actualidad anochece a las 9 p.m. en esa fecha. Es destacable la insistencia en el dato por parte de Ibarra: "era preciso el descubrimiento de la hermosa escultura, que al oscurecer del día 4 de Agosto del corriente año apareciera en las ruinas de Illici" (Ibarra Ruiz 1926: 197).

Entregada la Reina Mora $^{7}$ a su dueño, a nadie de sus coetáneos pareció importarle quién la había alumbrado, sencillamente unos jornaleros laboreando el terreno, tal como el propio Ibarra le expuso a P. Paris el día 11 de agosto cuando este llegó desde Madrid a Elche. Las gestiones de compra del francés fueron rápidas, pues logró tener cerrado el contrato con Manuel Campello Antón y Asunción Ibarra tan solo una semana después de su llegada, tal como confirma Ibarra Ruiz en su Efemérides no 122: "18 de agosto de 1897. Venta del busto!!! Mr. Pierre Paris ha comprado para el Museo del Louvre el hermoso busto que posee Campello, hallado el día 4 en $\mathrm{La}$ Alcudia por la suma de 4000 francos. No sé lo que me pasa", sucinta y claramente se lamenta de una pérdida que le tocaba muy adentro. Finalmente dará rienda suelta a ese desgarro interior con el traslado de la Dama a Alicante el día 30 de agosto: "Hoy se ha llevado el busto Mr. Paris. ¿Y esto no tiene remedio? ¿Y no hay una Ley en España que impida esto? Acaso porque un hombre no tenga afición a esas cosas ... ¿no se le puede impedir que venda esto al extranjero?" (Efemérides no 124 ¡Adiós al busto!). Es significativo el uso de la cursiva en la anterior frase,

\footnotetext{
${ }^{7}$ La escultura se marchó de España con dos apelativos, el espontáneo y popular de "reina mora" que le habían dado los braceros del Dr. Manuel Campello Antón en la inmediatez de su descubrimiento, y el de "busto de Elche" que le atribuyó Pedro Ibarra en todas sus descripciones. Se convirtió en la Dame d'Elche al subir al barco en Alicante de la mano de Pierre Paris, y consolidó el nombre durante su estancia en el Museo del Louvre. En el año 1941 volvió a España como Dama de Elche.
} 


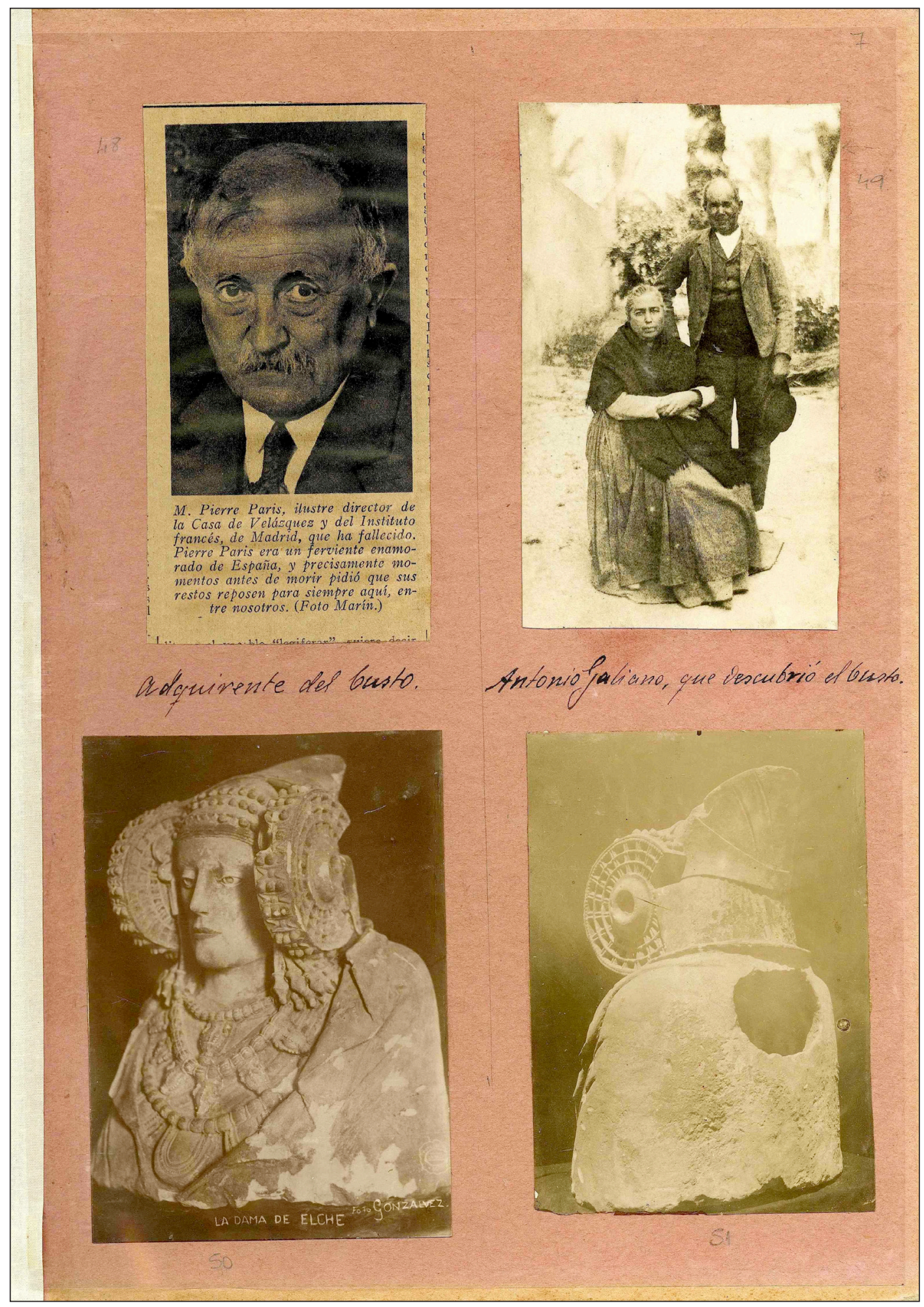

Figura 7. Hoja del álbum original de Pedro Ibarra con dos fotografías de la Dama, el recorte en prensa del fallecimiento de P. Paris en 1931 y la fotografía del capataz Galiano y su esposa (AHME). 
pues parece indicar la literalidad de la respuesta de Campello Antón a Ibarra Ruiz que, sin embargo, nunca testimonió el papel jugado por su sobrina Asunción Ibarra en la transacción. Los pormenores de la venta son relatados en primera persona por el protagonista, con diálogos entre los intervinientes como si fuese un vodevil (Paris 1907: 320-326), un tipo de redacción que llega incluso a justificar: “n'a pas toujours été fidèlement relaté; le rôle que j'ai joué dans l'achat du buste a plus d'une fois été dénaturé [...] J'ai donc cru devoir, aprés dix ans, raconter avec una fidélité de procès-verbal le détail de mes négociations avec le Docteur Campellos." (Paris 1907: 334). En su narración es donde se descubre claramente que fue la hija de Aureliano Ibarra la que accedió a la venta de la Dama, "C'est bien, mais si ma femme consent. Séance tenante l'accord est rédigé, signé, paraphé" (Paris 1907: 324), detalle poco divulgado que, sin embargo, no pasó inadvertido a García y Bellido: "Pues... aquí intervino la señora del doctor Campello, quien con reflexiones que no conocemos, pero que son fáciles de adivinar, llegó a convencer a su marido del interés que reportaría la venta" (García y Bellido 1943: 7). En esta línea se pronuncia la investigadora C. Papí que atribuye la venta a la necesidad de dinero por parte del matrimonio para la compra de una nueva finca (Papí 2005: 164; nota 11).

Una vez fuera de Elche, el periplo de la Dama, de nuevo, lo conocemos por su comprador, que afirma "Huit jours après [...] j'embarquais à Alicante le précieux colis qui devait arriver sans encombre" (Paris 1907: 325). Las andanzas del arqueólogo galo esa semana — del miércoles 18 que firmó, al martes 31 que partió rumbo a Cette (actual Sète) — son un punto opaco en el relato. Según T. Tortosa únicamente escribe en su diario que, entre los días 27 y 31, asistió a una corrida de toros en Alicante (Tortosa 1996: 217). Existen además unas declaraciones casi desconocidas de Clemencia Miró Maignon, hija del célebre escritor Gabriel Miró, al periodista Rico de Estasen, en las que le confiesa que la escultura estuvo hospedada en el consulado francés de Alicante — sito en la esquina de la C/ Foglietti y Alberola del barrio de Benalúa - durante "ocho o diez días". El episodio, que ella conocía por boca de su madre, la hija del cónsul francés Antonino Maignon Fauquier, su abuelo (Ramos Pérez 1996: 65, 84 y 162-163), está lleno de detalles muy curiosos, como que estuvo custodiada por dos guardia civiles solicitados por el cónsul, y que a la hora de partir la rodearon con saquitos de arena como medida de protección para el viaje (Rico de Estasen 1962). Esta confesión resulta cuanto menos extraña, ya que el alojamiento de la Dama en Benalúa solo pudo ser la noche del lunes
30 a la tarde del martes 31 , a las 16:00 h., momento en que fue subida al propio camarote de P. Paris: "La Dame d'Elche, tranquillement, dans ma cabine" (Paris 1907: 325), para vivir en suelo francés su etapa calificada "de destierro" por los autores que contaron su historia en el siglo xx (García y Bellido 1943: 7; Ramos Folqués 1944: 262).

\section{I94I. El RETORNO DE LA DAMA}

La Dama hizo el viaje de vuelta a España en un tren francés hasta Portbou el 8 de febrero de 1941. Llegó a Madrid el día 10 del mismo mes, para quedar finalmente instalada en el Museo del Prado el 27 de junio en la Sala 71 o rotonda "de la Dama de Elche", que fue el lugar donde poder ir a admirarla durante tres décadas (Fig. 8), en concreto hasta 1971, fecha en que -por la Orden Ministerial de 29 de enero de 1971- pasa a formar parte de los fondos del MAN $\left(n^{\circ} 1971 / X / I\right)$.

Su estancia en el Museo del Louvre de París duró 44 años, y en ese tiempo habían ido muriendo la mayoría de los protagonistas de aquel momento: el Dr. Campello en 1904, Asunción Ibarra en 1936, Pierre Paris en 1931, Pedro Ibarra en 1934, incluso algún testigo presencial de la Dama en casa del doctor Campello aquellos días de agosto, como el comprador de la finca en 1916 Rafael Ramos Bascuñana (Ibarra Ruiz 1926: 196) que murió en 1918, y que era el padre de un joven de 12 años llamado Alejandro Ramos Folqués. Su esposa, Encarnación Consuelo Folqués Sastre, viuda de Ramos, pasó — desde entonces y hasta 1942 - a ser la dueña de La Alcudia, y continuó adaptando el terreno para fines agrícolas.

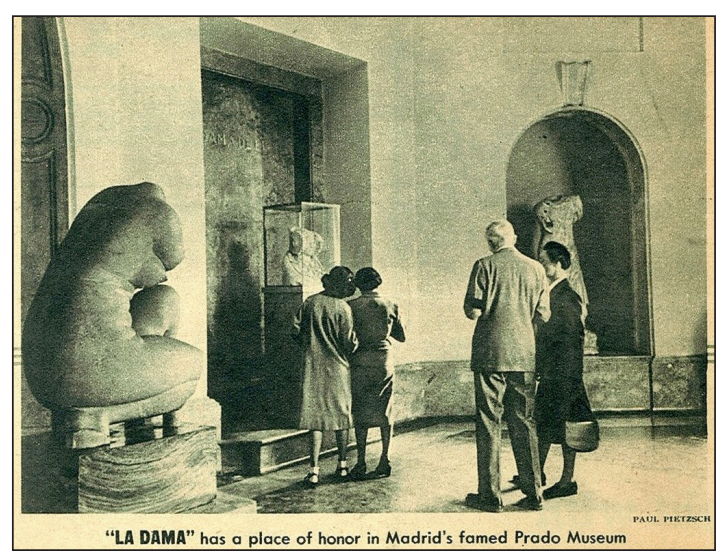

Figura 8. Fotografía de Paul Pietzsch de la Dama en el Museo del Prado. Publicada en el semanario norteamericano "This Week Magazine" en un artículo de Salvador Dalí de 6 de marzo de 1955. 
Desde su adolescencia Alejandro Ramos se aficionó a encontrar piezas arqueológicas en los periodos vacacionales hasta que, a su regreso de la contienda civil en junio del 1939, consiguió ser nombrado archivero municipal. La noticia del regreso de la Dama en febrero del 1941 le llegó en un momento en que estaba intentando poner orden en muchos frentes de su vida. Por un lado, la creación de un museo municipal con los fondos de Pedro Ibarra, y por otro las acciones para que le renovaran el permiso de excavación a su nombre que había conseguido en 1935 en época de la República, sin el cual su anhelo de ser el excavador de La Alcudia podía desvanecerse. Ese interés tan vivo se explica a raíz de la fatídica experiencia que había supuesto para su familia los sondeos de Antonio Vives Escudero en el yacimiento por imperativo legal a través de una Orden Ministerial con fecha 15 de febrero de 1923. Calificadas por Alejandro Ramos como "detestables", en sus relatos personales explica como quedaron las tierras de cultivo abiertas por las zanjas que realizó el numismático, unido al éxodo de las cajas con los materiales arqueológicos al MAN, cúmulo de hechos que supuso el acicate para llevar a cabo personalmente las excavaciones del yacimiento.

Hemos de resituarnos en aquellos convulsos tiempos para entender que el régimen de Franco unió su propaganda a objetivos arqueológicos que le convenían a su discurso patriótico para la formación de una dictadura apoyada en conceptos históricos sobre el origen y la raza. Un buen ejemplo de aquellas proclamas historicistas es el alegato de Ernesto Giménez Caballero, destacado miembro falangista que llegó incluso a pedir antes de su llegada-Gaceta Alicantina 1 de septiembre de 1940- que la Dama se instalara en Elche, artículo que le sirvió de base para la redacción del más conocido de enero de 1941 La Dama de Elche ;a su paisaje histórico!, inminente al regreso del busto a principios de febrero (Gutiérrez 2016: 79), argumentos que en aquel momento alentaron vanas esperanzas en algunos ilicitanos.

\section{i944. Manuel Campello Esclapez: un nuevo ACTOR ENTRA EN ESCENA}

En la capital, el arqueólogo Antonio García y Bellido tomó la delantera en la investigación y, en tan solo dos años, publicó el libro La Dama de Elche y el conjunto de piezas arqueológicas reingresadas en España en 1941, que se convertiría en una referencia. Por la dedicatoria en el original de la biblioteca de Alejandro Ramos, sabemos que el 7 de marzo de 1944 estuvo en Elche y que fue entonces cuando ambos hablaron de los originales de Pedro Ibarra que Alejando le mostró, así como del nuevo testigo presencial que el arqueólogo ilicitano había entrevistado, el jornalero Manuel Campello Esclapez, personaje que Alejandro Ramos sumó a la historia oficial de 1897. Éste, en la introducción de su opúsculo de 1945 de gráficas Uguina - de idéntico nombre y contenido al del artículo de 1944 en Archivo Español de Arqueología, La Dama de Elche. Nuevas aportaciones a su estudio-, explica que le ofreció a García y Bellido "los materiales que sobre esta escultura había ido recogiendo, especialmente los procedentes del archivo de D. Pedro Ibarra y los de campo [...] los estimó en gran manera, pero no quiso hacer uso de ellos" (Ramos Folqués 1945: 3), añadiendo que le invitó generosamente a que fuera él mismo quién los publicara en la revista.

El dato concreto que interesó a García y Bellido del nuevo testimonio fue la disposición del busto que, además, quedó definitivamente fijada en un dibujo de Alejandro $^{8}$ (Fig. 9), "que apareció metida en una especie de hornacina formada por dos losas a modo de suelo, y seis losas más, dos a cada lado y dos al fondo, colocadas verticalmente sobre las que formaban el suelo" (García y Bellido 1948: 152). Este nuevo dato fue decisivo para que el investigador consolidara su teoría de la baja datación de la Dama que había ido rebajando, para concluir que se trataba de una escultura funeraria aparecida en el interior de una casa urbana de la colonia cesariana de mediados del s. I a. C., "esta vez definitivamente, fijándola en un

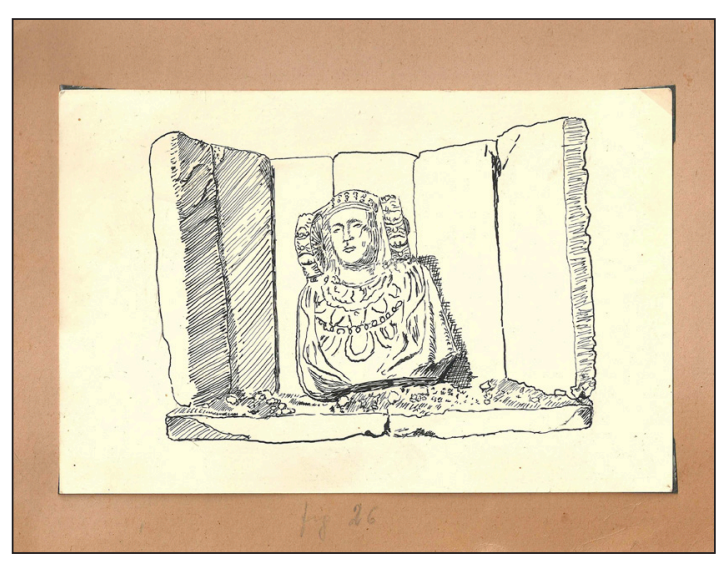

Figura 9. Dibujo original de A. Ramos del "esquema del modo cómo apareció el busto de Elche, según la narración de Manuel Campello" (Fondo ARF. Fundación L'Alcúdia).

\footnotetext{
${ }^{8}$ Él mismo califica textualmente su dibujo de mera interpretación: "En la figura 3 damos un esbozo que pretende interpretar la narración que sobre las circunstancias del hallazgo acabamos de transcribir de boca del obrero Manuel Campello" (Ramos Folqués 1944: 254), aunque con el tiempo, esa imagen ha quedado fijada como un cliché fotográfico totalmente fidedigno, tanto para investigadores como popularmente.
} 


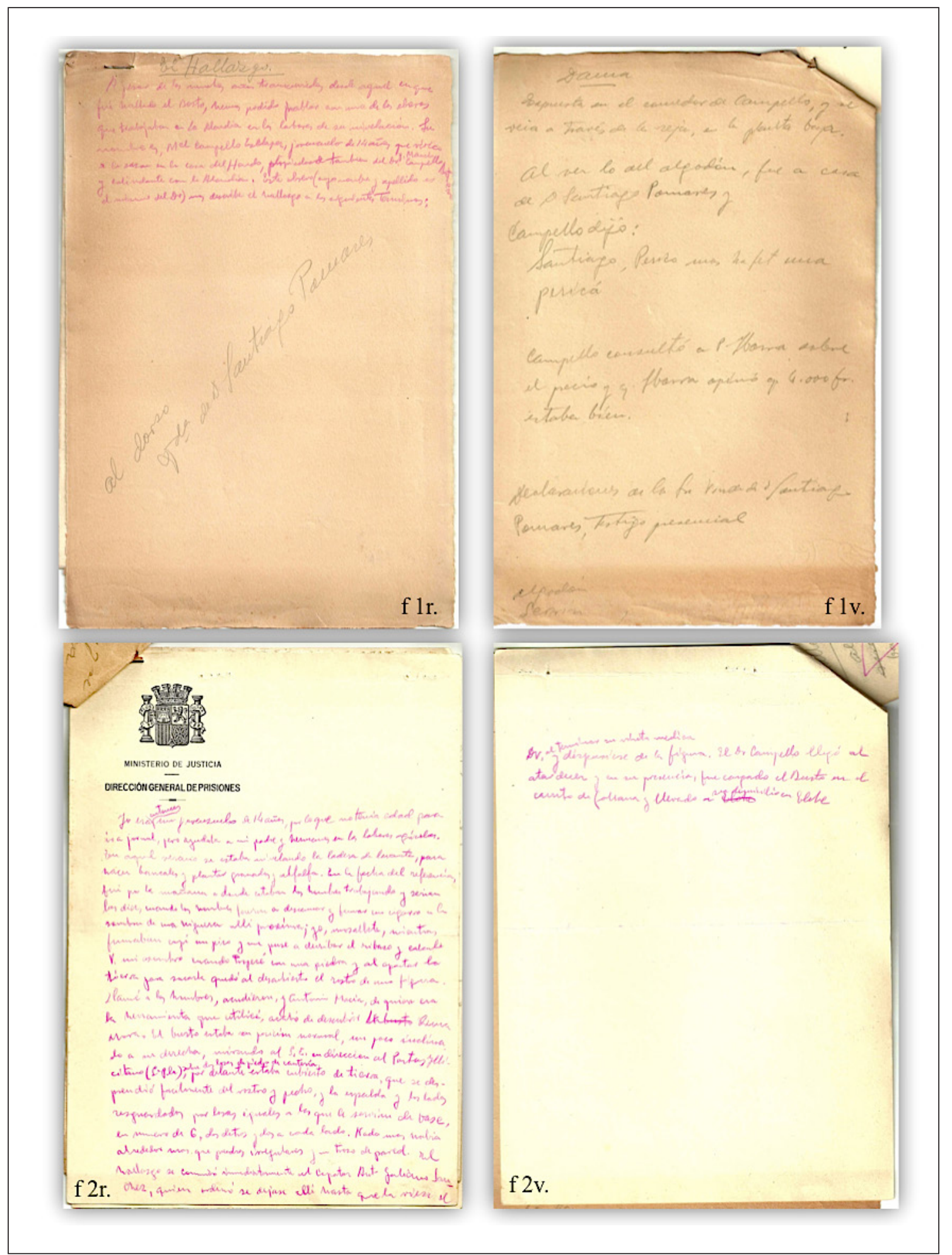

Figura 10. Documentos manuscritos de Ramos Folqués con el relato de M. Campello Esclapez para sus publicaciones sobre la Dama (Fondo ARF. Fundación L'Alcúdia). 
momento que debe rondar el cambio de Era" (García y Bellido 1948; 152).

Pero, ¿quién era aquel nuevo Campello?, hasta 1944 un absoluto desconocido en la historia del hallazgo. Es evidente que Pedro Ibarra no recogió su nombre en ningún documento porque, ni su informador, el capataz Galiano, ni nadie lo mencionó nunca. Alejandro Ramos cuenta que en esas fechas tuvo noticia de que aún vivía un testigo visual del hecho y fue a preguntarle. El resultado de la conversación lo escribió en primera persona, suponemos que para darle más verosimilitud y frescura al relato y, también, porque Manuel Campello solo hablaba valenciano y sus nociones de escritura debían ser muy elementales. De esa entrevista hemos encontrado el relato manuscrito ya elaborado por Alejandro Ramos, casi idéntico al de sus publicaciones (Fig. 10). La redacción original arranca del siguiente modo: "Yo era entonces un jovenzuelo de catorce años, por lo que no tenía edad para ir a jornal, pero ayudaba a mi padre y hermanos en las labores agrícolas", dato que es equívoco ya que, según su partida de nacimiento (Payá 1987: 352-353), Manuel Campello nació el 26 de agosto de 1879, realmente el 4 de agosto de 1897 le faltaban 22 días para cumplir 18 años, edad adulta que nunca admitió.

Del mismo modo, observamos cómo la narración deja entrever su urdimbre constructiva, las preguntas aproximadas que le debió hacer Alejandro Ramos a su testigo, a tenor del contenido: ¿qué pasó ese día?, ¿en qué posición estaba?, ¿qué había alrededor? y, ¿a quién se le comunicó el hallazgo? Algunas de las respuestas de Campello no coincidían con la información que Galiano dio a Ibarra en 1897: la hora del suceso a las diez de la mañana, la espera durante todo el día en La Alcudia, así como la llegada del doctor casi anocheciendo para llevarse personalmente la Dama a su casa de Elche. Otros detalles muy específicos, como el tipo de cultivos que iban a plantarse — granados y alfalfa—, la inclusión de la herramienta de Maciá para terminar de sacarla de la tierra con la frase, "Llamé a los hombres, acudieron, y Antonio Maciá, de quien era la herramienta que utilicé, acabó de desenterrar el busto de la reina mora", parece un añadido de Alejandro Ramos para nivelar el relato con el de P. Ibarra y dar verosimilitud a la presencia de ambos en el mismo momento. El dato de la dirección de la mirada al SE "en dirección al Portus Illicitanus (Sta. Pola)", así como el aviso al capataz -que anota con

\footnotetext{
${ }^{9}$ Pedro Ibarra también aportó en su día la orientación de la pieza: "el busto ha sido hallado en la parte más oriental de la loma de La Alcudia, frente a frente por donde asoma el astro del día” (Ibarra Ruiz 1926: 205). Si M. Campello coincidió
}

su nombre y dos apellidos como lo presentó Pedro Ibarra-, semejan beber de la fuente original. Creemos que Ramos Folqués quizás encajó los datos que él conocía con aquellos nuevos que Campello Esclapez le expondría de modo sencillo, en especial su presencia en la escena del hecho y la hora de aparición, dudas que han planeado siempre por su contradicción con el relato de Ibarra Ruiz. Rafael Ramos en su libro de 2003 explica esas "anomalías evidentes" — la identidad del descubridor y la hora del descubrimiento-, con una supuesta artimaña del capataz Galiano al tergiversar los datos para "silenciar los detalles del hallazgo al dueño de la finca" (Ramos Fernández 2003: 39), aunque en ese caso, la gran pregunta que queda en el aire sin respuesta es porqué se ocultó la intervención de Manuel Campello en la historia.

\section{La RECREACIÓN DE RAMOS FOLQUÉS}

Existe además otro dato del testimonio de Campello que ha pasado inadvertido hasta ahora, y es que también cambió el lugar del hallazgo 50 m más al sur en la línea de bancal. En los fondos documentales de Ramos Folqués hay dos fotografías algo diferentes del labrador con su típico blusón negro y gorra señalando con el dedo hacia el talud o bancal (Fig. 11), siendo la $\mathrm{n}^{\mathrm{o}} 1$ la única reproducida en compañía de la del hito de Ibarra (Fig. 2), con pies de foto referidos al "lugar del hallazgo de la Dama”. Al mostrar Ramos Folqués las dos fotografías juntas en la misma lámina (Ramos

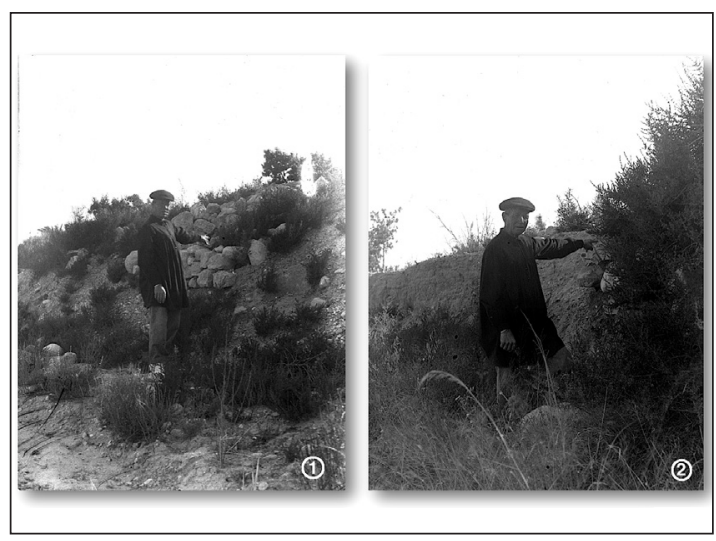

Figura 11. Dos fotografías de M. Campello posando para Alejandro Ramos en 1944. Las diferencias en la vegetación y la altura de las piedras que contiene el margen parecen indicar que no fueron realizadas en un único punto. (Fondo ARF. Fundación L'Alcúdia).

con señalar esta orientación, sin duda debió decir que estaba "mirando a Sta. Pola", y el topónimo del Portus Illicitanus, con seguridad, es un añadido de Alejandro Ramos. 


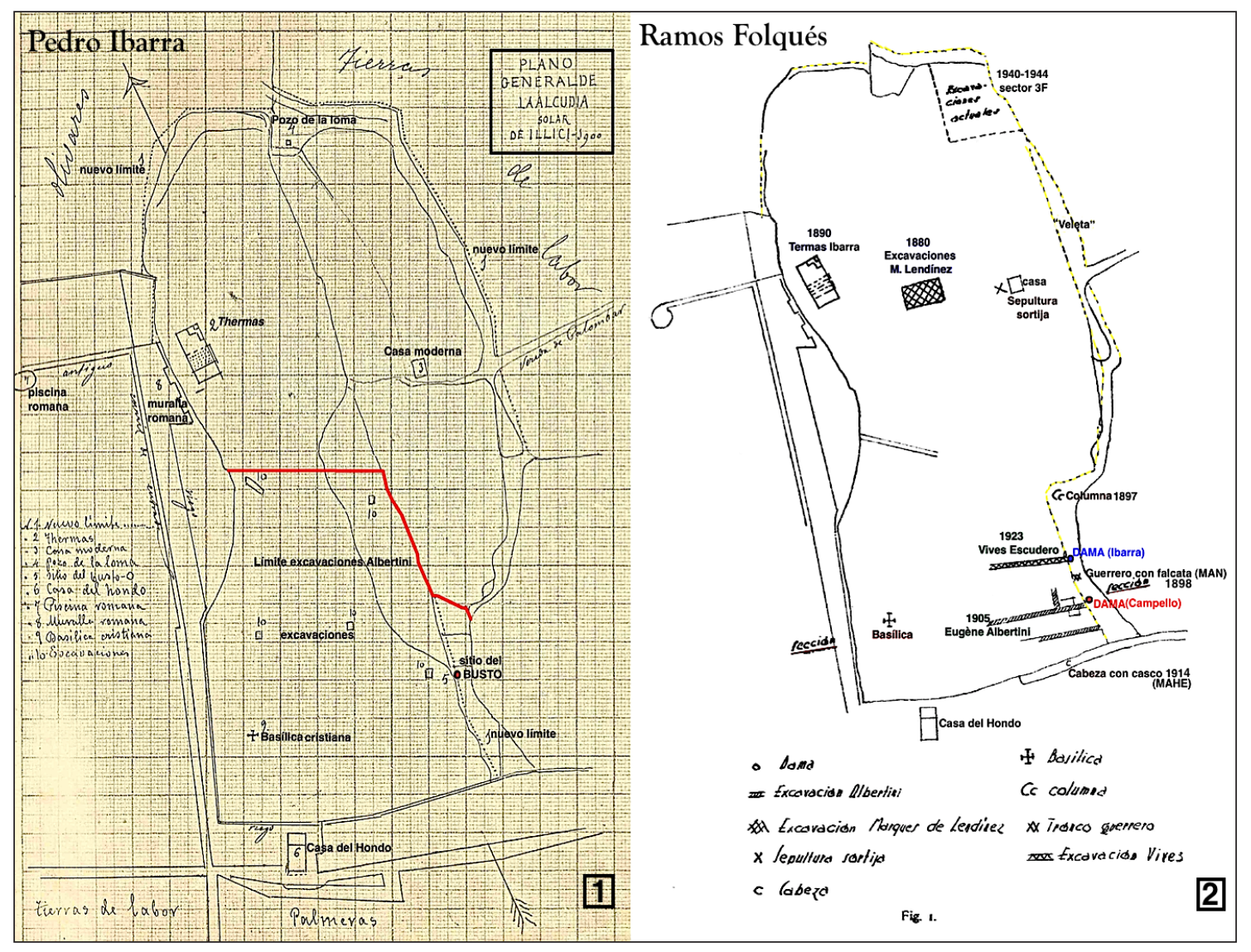

Figura 12. 1. Facsímil de un plano de 1900 de Pedro Ibarra en papel milimetrado. 2. Plano copiado del primero con la situación de las intervenciones en L'Alcúdia, según Alejandro Ramos (1944, 1945; fig. 1), rotulado por nosotros.

Folqués 1944: figs. 4-5; 1945: lám. III) siempre pareció claro que donde señalaba Manuel Campello era el mismo punto que el de la fita de P. Ibarra.

De nuevo, una mirada atenta al plano de Ibarra (Fig. 6) nos hizo advertir la diferencia de metros entre el punto donde actualmente se erige un monumento en honor al surgimiento y el monolito de Pedro Ibarra más al norte, sobre la línea de bancal. Y luego, visto con detenimiento el plano que presentó A. Ramos en sus publicaciones ${ }^{10}$-donde situó todas las intervenciones de las que tenía conocimiento-, se advertía en el cotejo de ambos que el punto de la

\footnotetext{
${ }^{10}$ Entre los documentos de Ramos Folqués hemos encontrado la fotocopia en papel milimetrado de un plano de Ibarra, a escala más reducida del grande (fig. 4). La autoría de Pedro Ibarra del original es evidente, por la letra y el dibujo, y con total seguridad podríamos afirmar que es este de donde Alejandro tomó el perfil para su primera publicación, tal como él mismo indica en su artículo de 1933: "croquis del plano de La Alcudia, según D. Pedro Ibarra” (Ramos Folqués 1933: 104; fig. I).
}

Dama lo había movido unos metros al sur, arrastrando por inercia las excavaciones de Eugène Albertini, que ahora quedaban niveladas con respecto a la basílica; sin embargo, la ubicación de la zanja de Vives Escudero de 1923 la mantuvo en el mismo lugar que el señalado por Ibarra en su plano como el "sitio del busto" (Fig. 12).

Además de la comparación planimétrica, hay testimonios fotográficos muy elocuentes. El primer interviú en prensa a M. Campello Esclapez, se lo hizo J. Rico de Estasen en La Alcudia el 1 de junio de 1946 y lo publicó, en repetidas ocasiones y medios, durante años. Una de las fotografías que le hizo muestra a Manuel Campello, que ese día vestía un blusón blanco, al lado de un margen alto donde se ve la fita de P. Ibarra y en el pie de foto reza: "Lugar donde fue encontrado el busto [...] en primer término el obrero ilicitano que lo descubrió" (Rico de Estasen 1948), aunque en otras ediciones cambia el texto por "las inmediaciones del lugar donde fue descubierta la valiosísima escultura". Y sin 


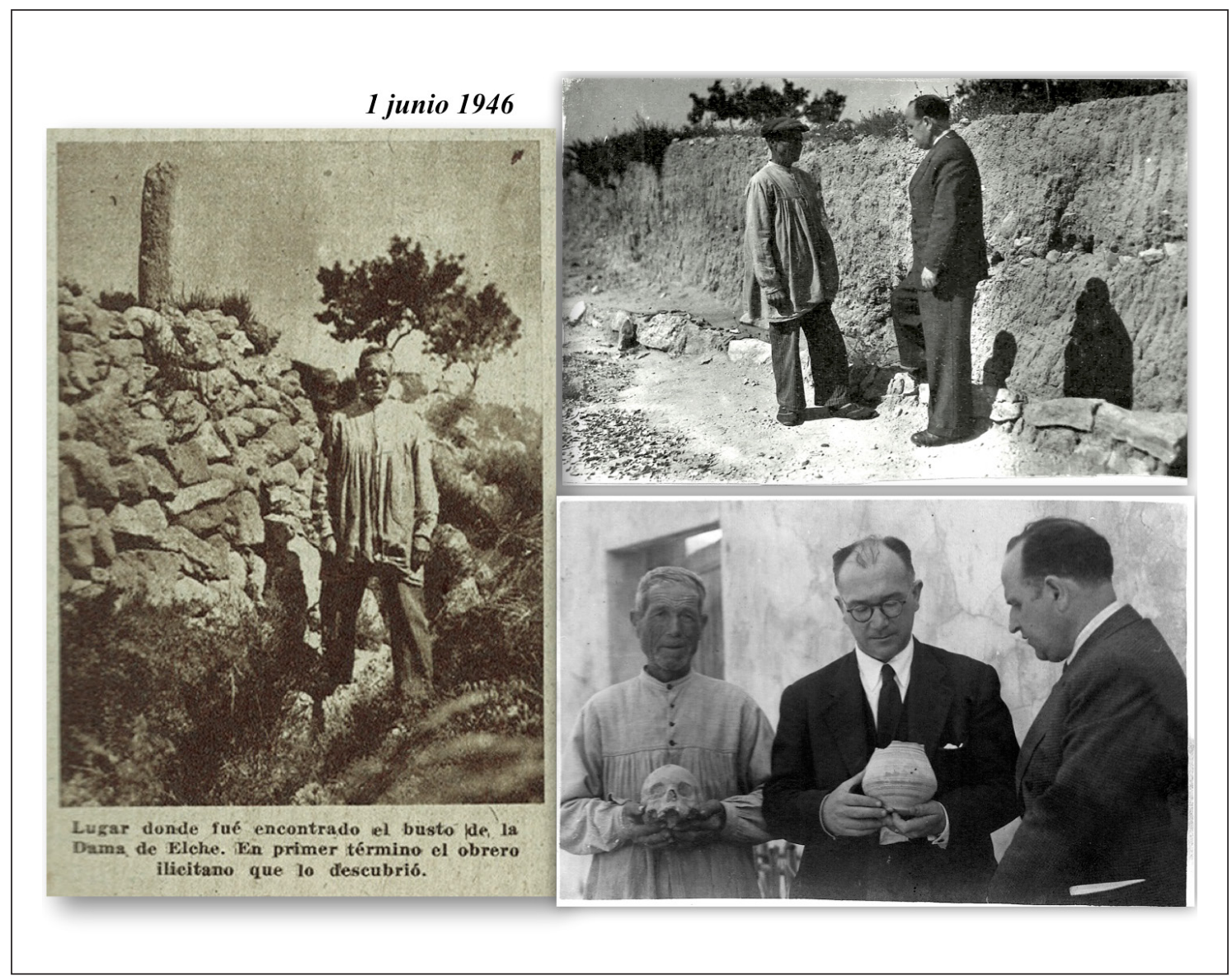

Figura 13. Fotografías de Rico de Estasen, Manuel Campello Esclapez y Alejandro Ramos en L'Alcúdia el domingo 1 de junio de 1946.

embargo, en otra fotografía se ve a Manuel Campello de pie delante de un talud más bajo y sin margen, donde únicamente hay una alineación de piedras en relación sobre las que el periodista apoya su pie derecho y aquí especifica que es "el lugar preciso del descubrimiento" (Fig. 13). Ambas imágenes demuestran la génesis de la duplicidad de los sitios, la columna o fita de Ibarra y el lugar señalado por el obrero que fue donde A. Ramos sondeó en 1945 en la "ladera de la Dama". De esa misma mañana, hay otra fotografía inédita de Ramos mostrándole al periodista una de las piezas que había sacado de la excavación de 1945 y Manuel Campello, mirando fijamente a cámara, sostiene con ambas manos el cráneo de uno los esqueletos que aparecieron en aquel sondeo (Fig. 13).

De modo definitivo, la bilocación del sitio quedó fijada sobre el terreno cuando A. Ramos pensó en hacer una recreación con los detalles trasmitidos por M. Campello: el cubículo de piedras que rodea- ba a la Dama y que él había dibujado (Fig. 9). La fotografía más antigua de la recreación que hemos podido documentar es de 1952, según rotuló en su álbum, en donde él mismo posa delante del nuevo hito que muestra los estratos aún inalterados por las cárcavas, con la tierra recién recortada y sin huellas de exposición a la climatología. A partir de 1956 esa fue la imagen de portada de los primeros folletos de visita al yacimiento, bajo la que se podía leer: "Reconstrucción hipotética del hallazgo de la Dama" (Fig. 14). También se detecta que, a pesar de instaurar el nuevo hito y lugar, lo curioso es que dicha duplicidad histórica siguió presente de manera física durante muchos años sobre el yacimiento, al menos hasta 1965, hecho patente en alguna imagen que muestra cómo, en el punto de fuga y sobre lo alto del margen, se mantenía enhiesta la columna de Ibarra a la vez que la recreación de Alejandro Ramos, que es objeto de la máxima atención por parte de los visitantes (Fig. 15). 


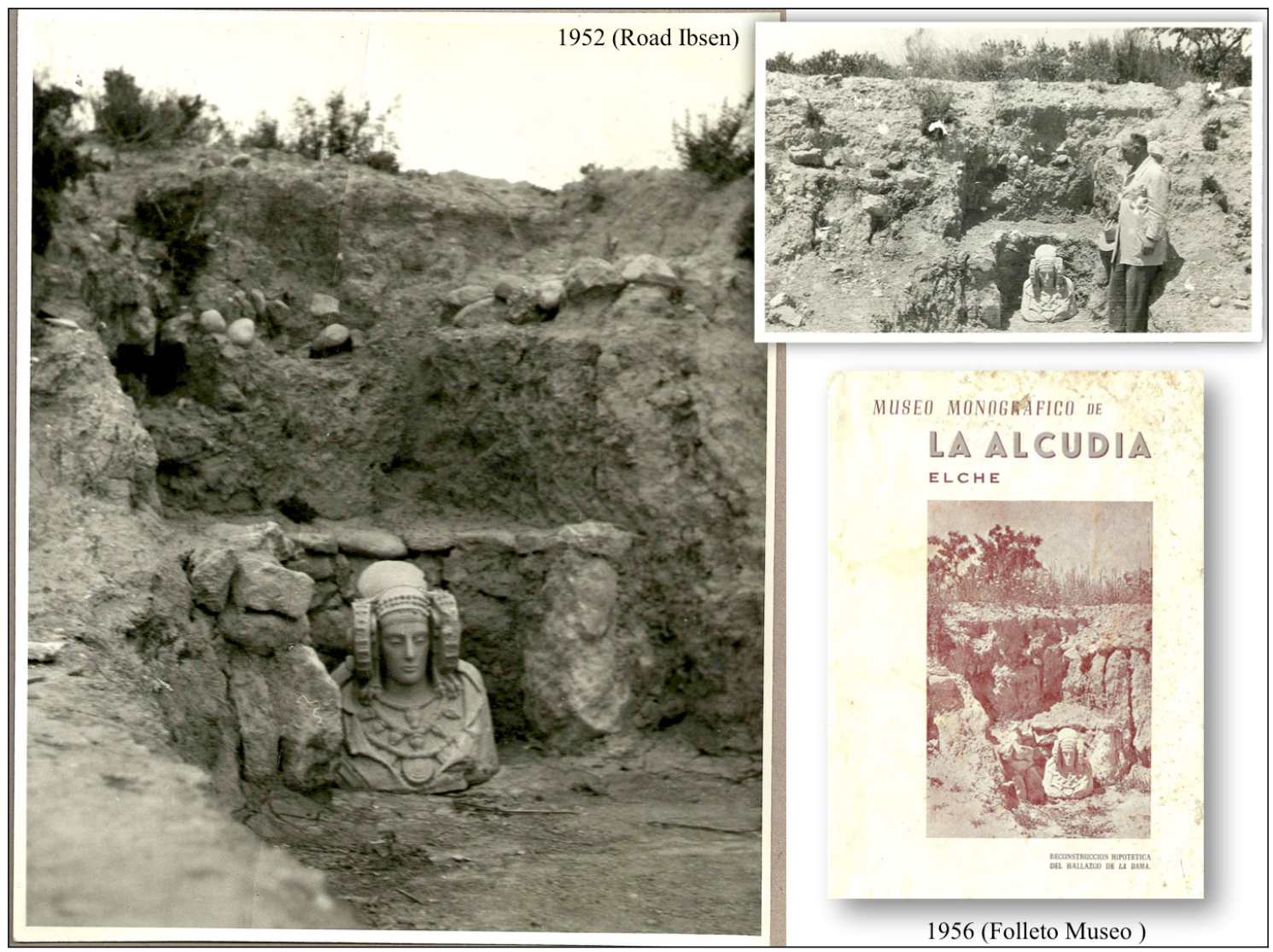

Figura 14. 1952. Documento fotográfico de la "reconstrucción hipotética" del descubrimiento con una réplica del busto en el lugar indicado por M. Campello (fotografías Road Ibsen. Fondo ARF. Fundación L'Alcúdia ).

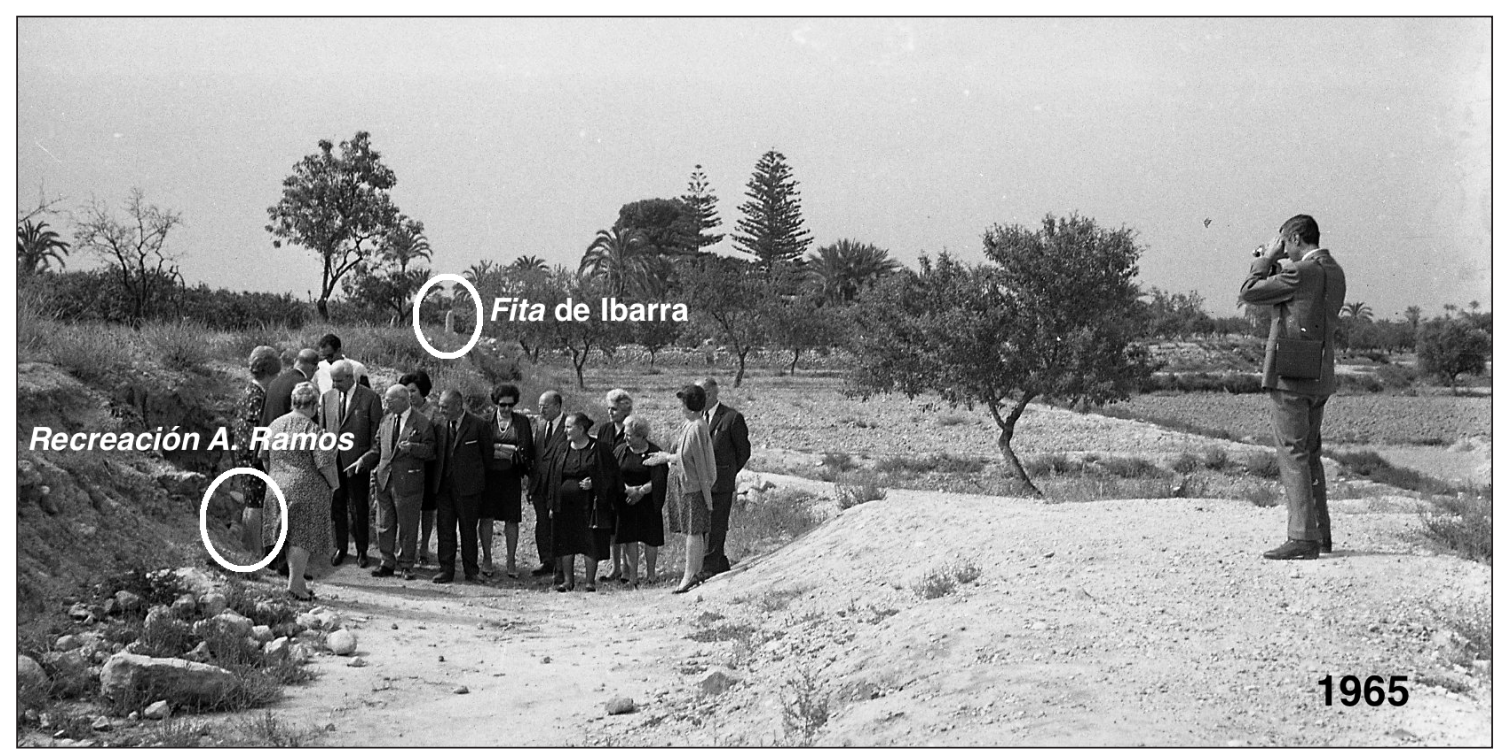

Figura 15. Fotografía de 1965 en donde se observa un grupo de visitantes en la recreación de Ramos Folqués y, en el punto de fuga y sobre el bancal, la columna de Pedro Ibarra. (Fondo ARF. Fundación L'Alcúdia). 


\section{EL CONTEXTO ARQUEOLÓGICO}

\section{LOS INTENTOS DE RECONSTRUCCIÓN DEL CONTEXTO ARQUEOLÓGICO DE LA DAMA}

En el relato del hallazgo, Ibarra Ruiz no refirió de modo taxativo sus averiguaciones sobre el contexto material y el modo en que apareció. Hay que sumergirse en una lectura atenta de sus datos y cotejar, incluso, su correspondencia, para llegar a saber esos detalles tan importantes. Resulta lógico pensar que al preguntarle a Galiano “¿En dónde?”, la respuesta fue sencillamente acompañarle al lugar exacto. Pero Ramos Folqués interpretó libremente este episodio "Ibarra no presenció el descubrimiento, fue al día siguiente inquiriendo las noticias que pudo de los obreros y capataz, quienes no interrumpieron sus labores por el hecho del hallazgo, sino al contrario, siguieron destruyendo las paredes y demás construcciones" (Ramos Folqués 1948: 154), aunque comprobamos que en el testimonio original, Ibarra solo describe la materialidad de lo que ve: "Inexploradas masas de gruesos paredones y pavimentos de mortero, esperan en el punto mismo del hallazgo su exploración científica" (Ibarra Ruiz 1926: 205).

El primer investigador que interpeló por el sitio y el contexto fue J. R. Mélida:

"Lo que no declara el artículo y nosotros podemos hacerlo, merced á [sic.] las noticias particulares que por satisfacer nuestra curiosidad nos remitió el mismo D. Pedro Ibarra [...]; que el descubrimiento fué [sic.] casual; que el punto en que, ocurrió fué [sic.] hacia el medio del declive producido en aquella tierra [...], y que no sé encontró sólo el busto, pues junto a él aparecieron infinitos fragmentos cerámicos de tres clases, las tres constantes en la colección ilicitana [...] barro negro del género italo-griego; barro blanco decorado con figuras rojizas ornamentales de carácter ibérico, y barro tarraconense llamado saguntino; dos o tres esqueletos humanos, un trozo de fuste de columna, de 1,20 m. de longitud, y gran cantidad de piedra de construcción" (Mélida 1897: 427-428).

Años más tarde el propio Pedro Ibarra en su libro de 1926 puntualizó esos datos —en respuesta a Theodor Reinach y a su teoría de que el contexto de la Dama era de necrópolis- ofrecidos por él mismo y que no eran correctos, siendo esta declaración concluyente y aclaratoria:

"Los aludidos tiestos y huesos pertenecen a otros yacimientos. En la loma de La Alcudia se presenta la cerámica en gran abundancia y por todas partes. El busto solo estaba acompañado en el punto del talud o plano inclinado donde fue hallado, por mucha piedra irregular caliza sin labrar. El fuste de columna, de un diámetro infinitamente menor que el diámetro de la base del busto, y sin collarino ni otra suerte de remate, sino simplemente un trozo de poco más de un metro, fué [sic] extraído de otro hoyo abierto a más de cincuenta metros del sitio donde se encontró la escultura" (Ibarra Ruiz 1926: 210; nota 2).

A la confusión de datos contribuyó sin duda la redacción de la efemérides $\mathrm{n}^{\circ} 126$ en su libro, pues duraba dos meses: "De 6 de agosto a 8 de octubre: Excavación en la loma: hallazgo de dos sepulturas: algunos objetos" (Ibarra Ruiz 1926: 155), cuando en el documento original de la efemérides 126 se acredita que las sepulturas y una sortija de plata se hallaron el día 8 de octubre de 1897 cerca de la casa (AHME Sign.: 70-B, no 30.3). Creemos que esta dilatada temporalidad, unida a su vaga descripción en fechas consiguientes al hallazgo de la Dama, alimentaron la falsa creencia de que esos trabajos se habían hecho en el mismo sitio del busto, cuando se comprueba que no fue así.

La abundancia de piedra en las tareas la expuso también el capataz Galiano al afirmar que el busto hubiera desaparecido por "creerla una de tantas piedras como venían extrayéndose de aquel sitio" (Ibarra Ruiz 1926: 195). Tan gran acumulación de cantos hizo que el archivero sentenciara que la Dama estaba incluida en la línea de muralla: "El hecho pues de haberse encontrado nuestra escultura en el emplazamiento de las murallas de Illici, prueba que no debe ser anterior a la fundación, o mejor, restauración de la colonia por Julio César". Esta deducción le llevó a la siguiente; que debió estar de pie:

"El sitio en que estaba la media figura, demuestra claramente que el ídolo estuvo plantado hasta los últimos tiempos de la existencia de la población romana, pues no es creíble que una escultura del tamaño de la que es objeto en estas líneas, permaneciera intacta en la superficie del terreno, sin sufrir deterioro alguno; y precisamente esa conservación y situación de la escultura dentro de Illici demuestran que no debe ser anterior a la venida de los romanos de Illici" (Ibarra Ruiz 1926: 205).

Hemos visto que a esta interpretación sobre la postura y la fecha de la Dama finalmente se sumó A. García y Bellido (1948: 152), e incluso Ramos Folqués en un primer momento influenciado por éste y con los datos de los materiales "inéditos" que había extraído cerca del lugar en una urgencia motivada por 


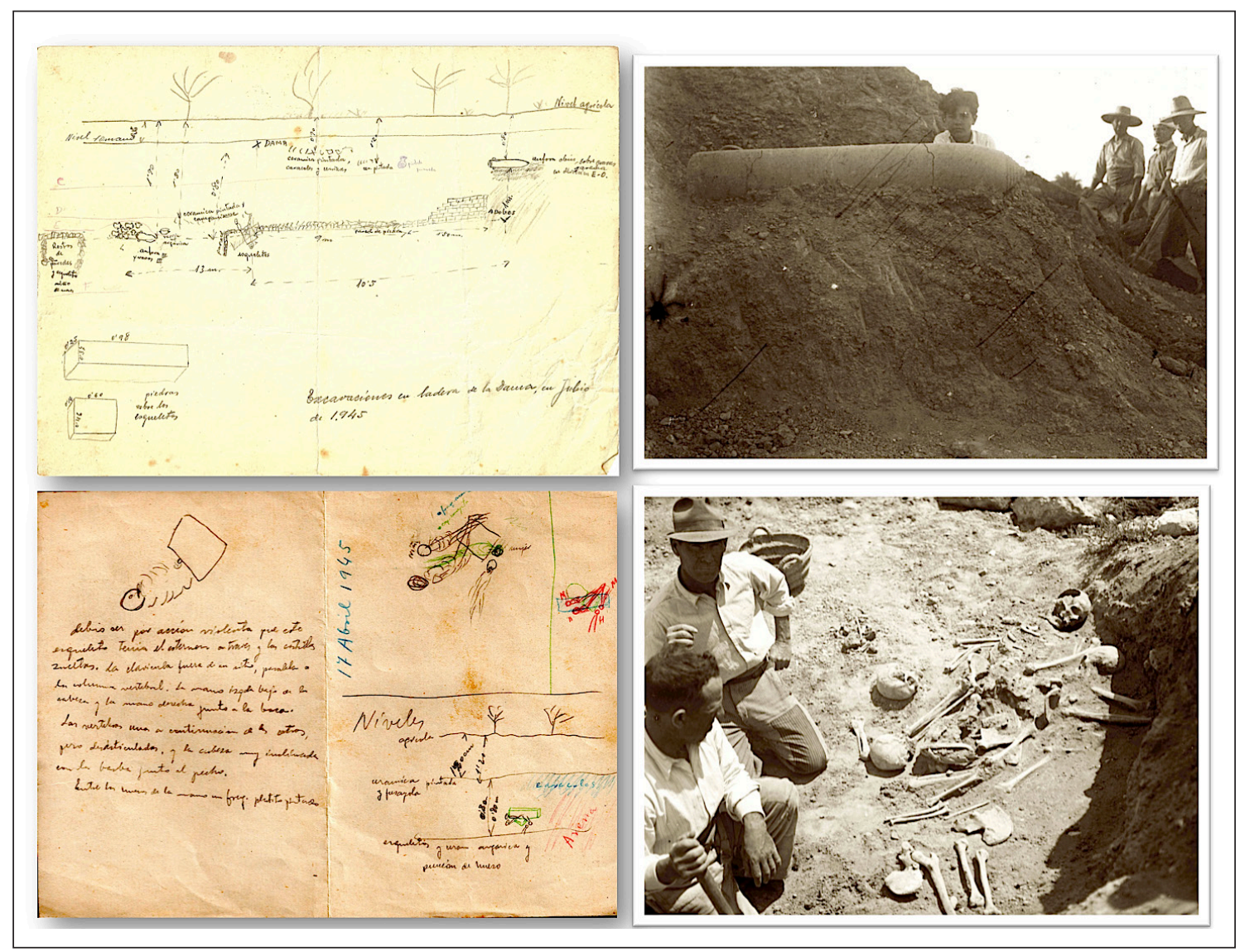

Figura 16. Croquis estratigráfico, apunte y fotografías de las excavaciones de Ramos Folqués de 1945 en "la ladera de la Dama".

las labores agrícolas en 1940; dice textualmente que "la época del célebre busto se aparta del s. v y se aproxima a época romana" (Ramos Folqués 1944: 267; 1945: 30). Se puede comprobar que las dos primeras ediciones de A. Ramos Folqués sobre la Dama están fuertemente influenciadas por A. García y Bellido que llegó incluso a corregirle, de puño y letra, el original del artículo de 1944 del arqueólogo ilicitano.

La idea de averiguar la estratigrafía y cronología de la Dama obsesionó a Alejandro Ramos desde que Campello Esclapez le indicara "sin titubeo alguno" el nuevo sitio.

"Sabedores que uno de los trabajadores que se hallaba en La Alcudia aquel 4 de agosto, y que habitaba en la finca colindante, vive todavía, intentamos reconstruir la forma del hallazgo, llevándonos a dicho obrero, Manuel Campello Esclapez, a la finca de La Alcudia, y puesto en antecedentes de nuestros deseos, nos condujo al lugar del hallazgo, señalándonos el nivel en que recordaba fue encontrada la Dama, lugar que coincide con el descrito por Ibarra y a unos 50 metros del norte del límite sur de la loma. Las indicaciones de este obrero, que con seguridad y sin titubeo alguno nos había mostrado el lugar del emplazamiento del busto y la profundidad a que se hallaba, relacionándolo con la situación de los árboles entonces existentes, y las acequias de riego, las tomamos como guía para iniciar unas exploraciones en dicho lugar, las que, nos han revelado datos que consideramos de especial interés para fijar la cronología de la Dama" (Ramos Folqués 1948: 155-156).

Esta larga exposición de las motivaciones de A. Ramos es prueba fehaciente de que éste creyó en el testimonio del lugar nuevo de Campello, aunque hemos de hacer notar que aquí no lo trata de descubridor, como hiciera en 1944 y 1945, sino como testigo presencial. De igual modo, opinamos que el detalle de si fue o no el descubridor de la escultura resulta un dato irrelevante por su casuística; a día de hoy es una mera anécdota que caló en los medios por su idealismo. Lo trascendente para la investigación arqueológica es que su testimonio fuera auténtico 


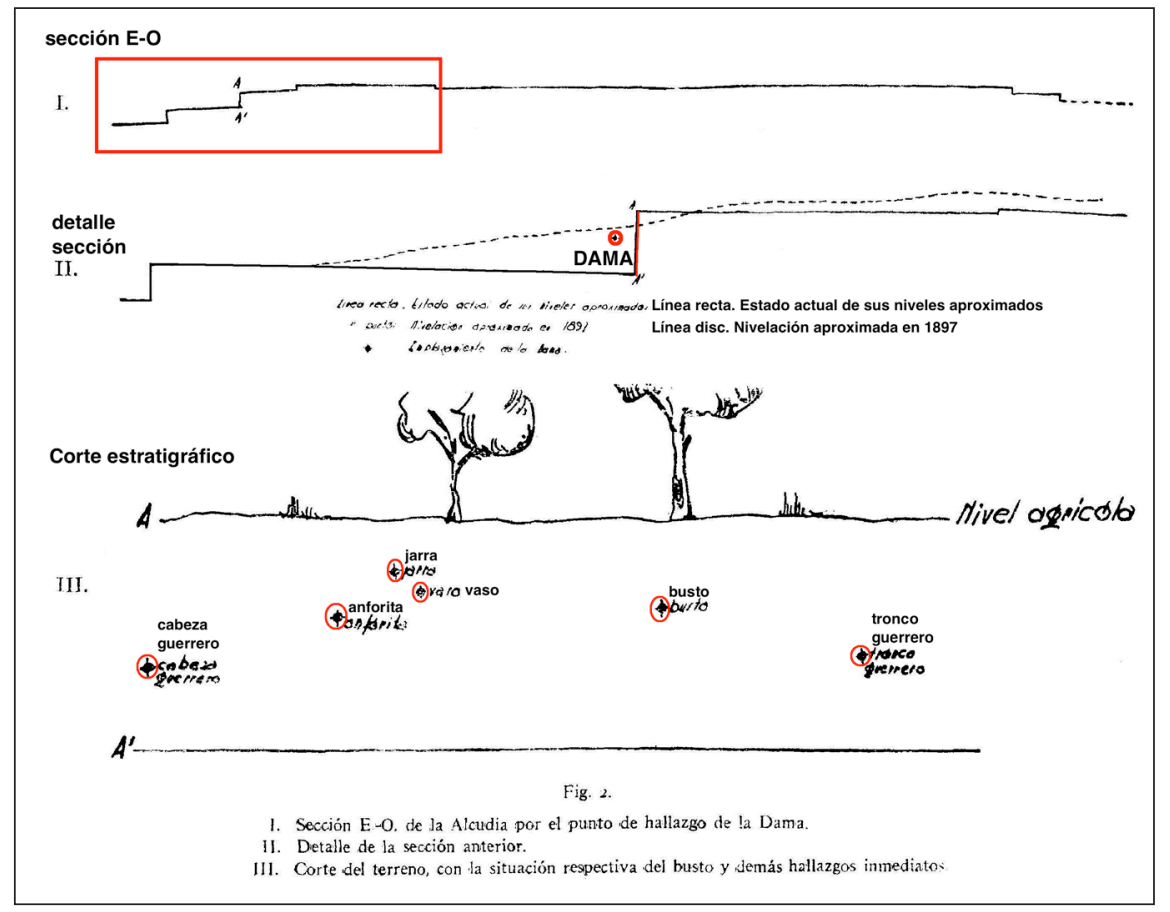

Figura 17. Sección E-O de la superficie de L'Alcúdia de Ramos Folqués (1944; fig. 2).

por estar presente o, incluso, por haberlo sabido de su padre y hermano mayor, que sí formaban parte de la cuadrilla aquel 4 de agosto de 1897.

Las primeras "calicatas" exploratorias las realizaría en 1945 y parece que Antonio Beltrán tuvo algo que ver en ellas, pues así lo manifestó en el homenaje a la muerte de Ramos Folqués en 1984, "juntos hicimos una cata junto al lugar de la Dama de Elche, en la Alcudia, para hallar cerámicas púnicas” (Beltrán 1993: 57), noticia que nunca desveló Alejandro Ramos. Estos trabajos están reflejados en unos escuetos apuntes en hojas sueltas, siendo destacable el croquis inédito de la estratigrafía y las fotografías de los trabajos (Fig. 16), documentos que muestran el desmonte del bancal con una praxis de excavación inadecuada para el talud, pues corta los estratos en vertical, sin respetar el supuesto depósito inclinado que estos tendrían de manera natural o antrópica. Un ejemplo de ello son los esqueletos y las grandes losas — lanzados o tirados intencionadamente en "acción violenta" según Ramos Folqués - que le aparecieron en la base del desnivel, los que relaciona con una hipotética "vasija argárica" cuyo dibujo más bien parece corresponder a una marmita tardía con asas de lengüeta. Esta enigmática acción explicaría la complexión anatómica de los restos humanos, no así la compleja relación estratigráfica con otros materiales que Ramos Folqués colocó al mismo nivel, como un ánfora y unos anforiscos en miniatura de tipología fenicia (Fig. 16), cuestiones estas que hay que tener muy en cuenta para llegar a conclusiones crono-estratigráficas en este tipo de depósitos tan alterados por la acción erosiva natural y antrópica ${ }^{11}$.

\section{“Gruesos Paredones" como alojamiento}

Para deducir cómo fue encontrada y extraída la Dama es necesario averiguar las acciones de aquellos jornaleros en 1897 para hacer una superficie llana cultivable. Al mirar con detalle la sección E-O (A-A') que Ramos Folqués publicó en sus trabajos (1944: 259, fig. 2; 1945: 9, fig. 2), ayuda a entender que lo que estuvieron haciendo los obreros del doctor Campello era vaciar de tierra y de piedras un talud artificial creado con el tiempo (Fig. 17), muy posiblemente la muralla que Pedro Ibarra mencionó como alojamiento de la Dama, la que debiera encontrarse semiderruida y expoliada desde antiguo. Estos procesos degenerativos bien pudieran ser comparables a los restos de la muralla augustea del frente occidental

${ }^{11}$ En 2017 de nuevo ha sido abierta en excavación aquella zona. Dirigida por los investigadores José y Héctor Uroz, con probabilidad sus resultados aportarán luz a las incógnitas que la excavación de Ramos Folqués de 1945 ya le planteó a él mismo. 
que pudimos estudiar en la excavación de 2006-2008 y que mostró interesantes datos sobre su estructura y composición. Estaba hecha sobre un zócalo de piedra y rellena de tierra, con adobes en el alzado, los que le daban más plasticidad y resistencia a la vez (Tendero y Ronda 2014: 238). Se comprobó además que ya a finales del s. II d. n. e. sufrió expolios continuados de la piedra contenedora, lo que aceleró su erosión y ruina, quedando al aire incluso el núcleo de tierra (Tendero 2016: 117), situación quizás análoga a la que pudieron haber sufrido los restos constructivos donde fue encontrada la Dama.

Ramos Folqués presentó también —en la misma figura 2- el croquis de un perfil estratigráfico con todos los hallazgos escultóricos conocidos hasta entonces por él, aunque los situó a distintas alturas y agrupados de modo irreal, ya que se comprueba que habían aparecido en puntos alejados entre sí, en distintos momentos y fechas (Fig. 17). El "guerrero con falcata", propiedad actual del $\mathrm{MAN}^{12}$, lo hallaron Ibarra y Paris el mismo día que plantaron la "fita", el 13 de junio de 1898, como consta en la Efemérides no 147:

"En la parte baja de la loma, y en el cauce mismo de una acequia de riego provisional, que han abierto para regar el bancal de alfalfa roturado recientemente a levante de la loma y... cual no ha sido nuestra sorpresa al arrancar dicha piedra, ver un tronco de un cuerpo de un guerrero seccionado por la cintura llevando delante, sujeta con una correa o tahalí, una espada o falcata, con el mango primorosamente trabajado. El descubrimiento nos ha complacido en extremo a todos los que allí estábamos. Ha sido clasificado por Mr. París, como obra de estilo ibérico, contemporánea del famoso busto, viniendo su presencia, a realzar la de aquel magnífico ejemplar, y demostrarnos por otra parte, la posibilidad de que no estaría sólo en la loma, el célebre resto greco-romano".

Del mismo día son las dos piezas arquitectónicas que también regresaron con la Dama, un fragmento de capitel de pilastra (García y Bellido 1943: 69-70; fig. 73, Lám. IX) y también un fragmento arquitectónico con volutas combinadas (García y Bellido 1943: 71, Lám. X), no así la "cabeza con casco" que surgió el 11 de noviembre de 1914 "Detrás de la Casa del Hondo, siguiendo el margen que separa la loma de los del comienzo de la casa, están abriendo un cauce para

${ }^{12}$ Esta escultura fue ofrecida en compra por el Dr. Campello Antón al museo del Louvre en 1899. Así se desprende en una carta dirigida a Pierre Paris fechada el 3 de diciembre -publicada por Ramos Fernández (2011: 125)-, y que finalmente regresó con la Dama en el lote de piezas ibéricas del intercambio de 1941 (García y Bellido 1943: 64-66) riego [...] he recogido una cabeza ibérica de tamaño natural en piedra caliza, que aún cuando muy estropeado, se puede apreciar que lleva casco" (Efemérides $\mathrm{n}^{\circ}$ 1129), custodiada en el Museo Arqueológico de Historia de Elche. Es cierto que todas ellas surgen en la línea que circunvala la pequeña eminencia del terreno en la zona sureste (Fig. 12.2), en el supuesto perfil de aquel posible recinto murado. Pero la diferencia entre estas esculturas y el conjunto de las que han ido aflorando en el yacimiento con la Dama, es el buen estado de conservación del busto.

\section{La DaMa EN RELACIÓN CON OTRAS ESCULTURAS IBÉ- RICAS DE L'AlCÚDIA}

La respuesta a la incógnita sobre su modo de aparición y preservación pasa por analizar la finisecular metamorfosis de las antiguas ruinas ilicitanas. Se tiene constancia de que Alejandro Ramos tras la guerra civil, en 1940, lo primero que hizo fue buscar esa muralla "de Levante" con el fin de comprobar la noticia de 1621, los famosos "dos mil y veynte pasos" que Cristóbal Sanz midió tras circunvalar un lienzo que, al parecer, aún rodeaba las ruinas de $\mathrm{La}$ Alcudia en el s. XVII. Pero los resultados según él fueron negativos (Ramos Folqués 1955: 113), y nos preguntamos si, como hemos visto, los obreros con su trabajo acabarían de desdibujar la ya expoliada muralla, resultando entonces muy lógica su incorporeidad.

Gran parte del perfil de La Alcudia se estuvo allanando y ampliando durante 1897, 1898 y 1899, dando como resultado la génesis de otro bancal a un nivel de cota más bajo que Ramos Folqués conoció como "la veleta", límite que Ibarra Ruiz marcó con una línea de puntos -n 1 "nuevo límite" - en su plano de 1900 (Fig. 12.1) ${ }^{13}$. Justo en ese límite o veleta, "a Levante de Villa Illice" y cerca del camino del Borrocat, Ramos Folqués comenzó a excavar en abril de 1952 muy cerca de la casa. Detectó una acumulación de piedras que fue asimilada como una muralla de 1,50 m de ancho cuya base estaba compuesta por piedras calizas mezcladas con restos arquitectónicos y

\footnotetext{
${ }^{13}$ Hacia mediados del siglo xIX el doctor Campello compró los terrenos a tres propietarios distintos, y por medio de agrupación catastral compuso la finca de La Alcudia tal como la conocemos hoy. Sabemos también que era un lugar pedregoso en el que emergían las ruinas, y que el médico puso su empeño y recursos para convertirlo en una finca cultivable (Ibarra Ruiz 1926: 191-192). Esto lo hizo paulatinamente, y la primera acción de que tenemos constancia fue en el noroeste en el "verano de 1889" cuando apareció el lienzo con casetones de refuerzo de las denominadas Thermas Occidentales excavadas por Ibarra Ruiz un año después (1926: 186-189).
} 


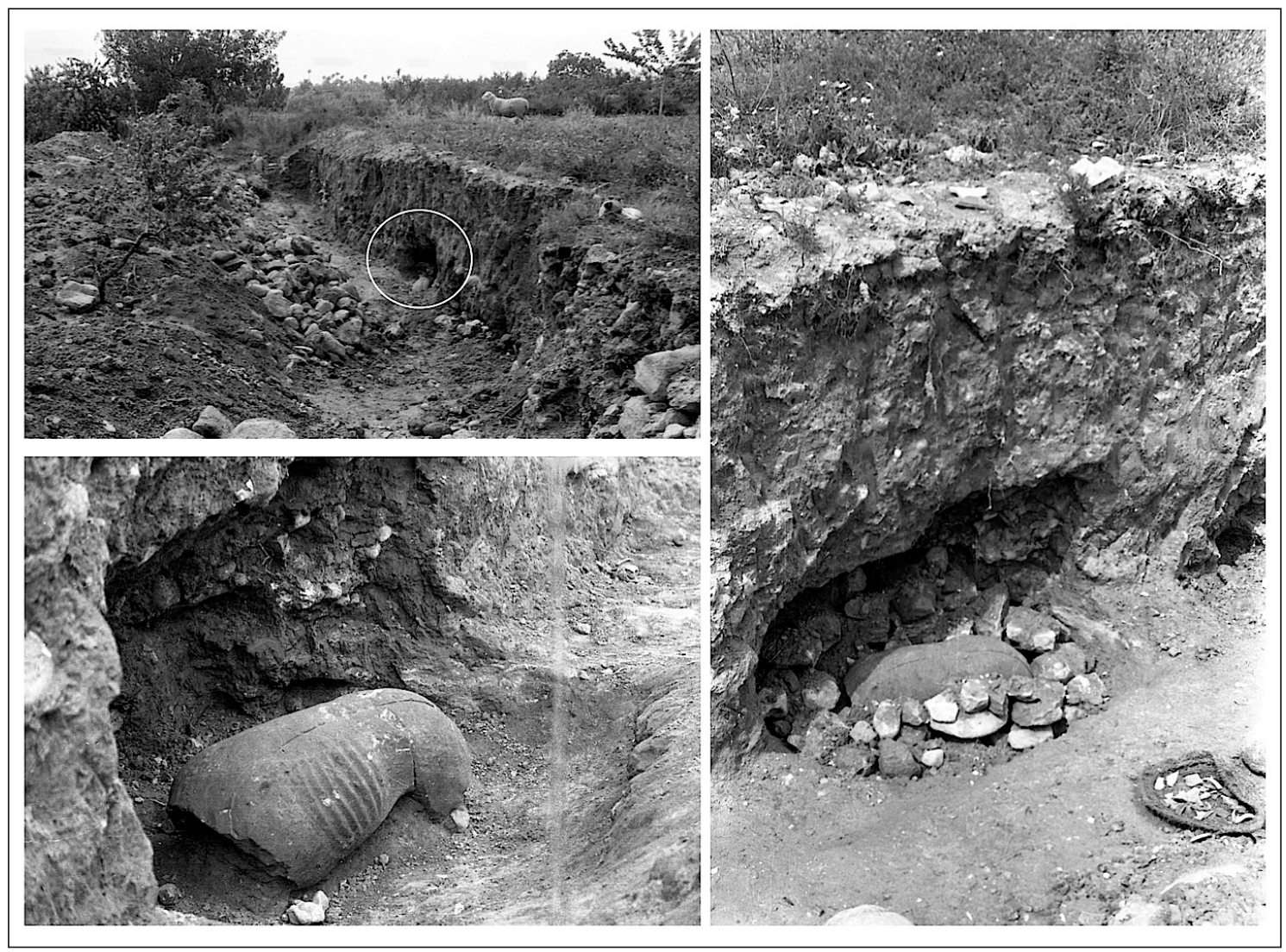

Figura 18. Fotografías del momento del hallazgo de la escultura de la leona o "bicha" en el talud Este de L'Alcúdia el 12 de abril de 1952 (fotografías A. Ramos).

esculturas. Esta estructura, que bautizó como "muralla púnica", continuaba hacia el sur —ocupa los actuales sectores $6 \mathrm{~F}$ y $7 \mathrm{~F}$ - y fue despejándola en distintas intervenciones. En 1952 le surgió, como una piedra más, la cabeza de esfinge (LA-620), en enero de 1955 una cabeza de équido (LA-806) que le apareció en la segunda fila de piedras de la base de esa muralla, cuya cimentación está cuajada de elementos arquitectónicos y escultóricos reaprovechados como piedra de construcción. De todos los hallazgos en aquella zona hay uno que requirió especialmente su atención, un cuerpo falto de cabeza y sin extremidades inferiores, que él reconoció como la figura de una leona o "bicha”, como también la denominaba. Esta escultura, que en origen debió coronar algún pilar estela en una necrópolis ibérica, le surgió encajonada por piedras sin labrar en un punto, quizás del interior de esa posible muralla, y según él in situ "allí había sido colocado deliberadamente como lo demuestra el hecho de estar calzado o entibado con piedras para que conservase una posición determinada y, además le rodearon de una especie de murete de piedra seca, como para preservarle de posibles atentados" (Ramos Folqués 1955: 11) (Fig. 18). Pero mucho más expresivo resulta su apunte en el diario:

"Al profundizar el zanjón de cata en la veleta, en nivel junto a la tierra virgen [había] varias piedras rodeando el torso de una leona (?) de mediano tamaño, en piedra blanquecina. Es de notar que las piedras que la rodean fueron puestas con cuidado de no rozar la escultura para no estropearla más. La pata izquierda está entibada con una piedra pequeña para equilibrar la figura. [...] Recuerdo que Ibarra dice que la Dama estaba entre piedras y Campello entre losas, ¿Estaría como esta pieza, escondida?" (Ramos Folqués y Ronda 2018: f. 42r. diario $n^{\circ} 14$ de 1952).

Estas reflexiones sobre la similitud entre ambos hallazgos demuestran que Ramos Folqués valoraba, tanto el testimonio de Ibarra, como los detalles que le contó Campello Esclapez en lo referente al modo de aparición de la Dama que motivaron su famoso dibujo (Fig. 9) y posterior recreación (Fig. 14). 


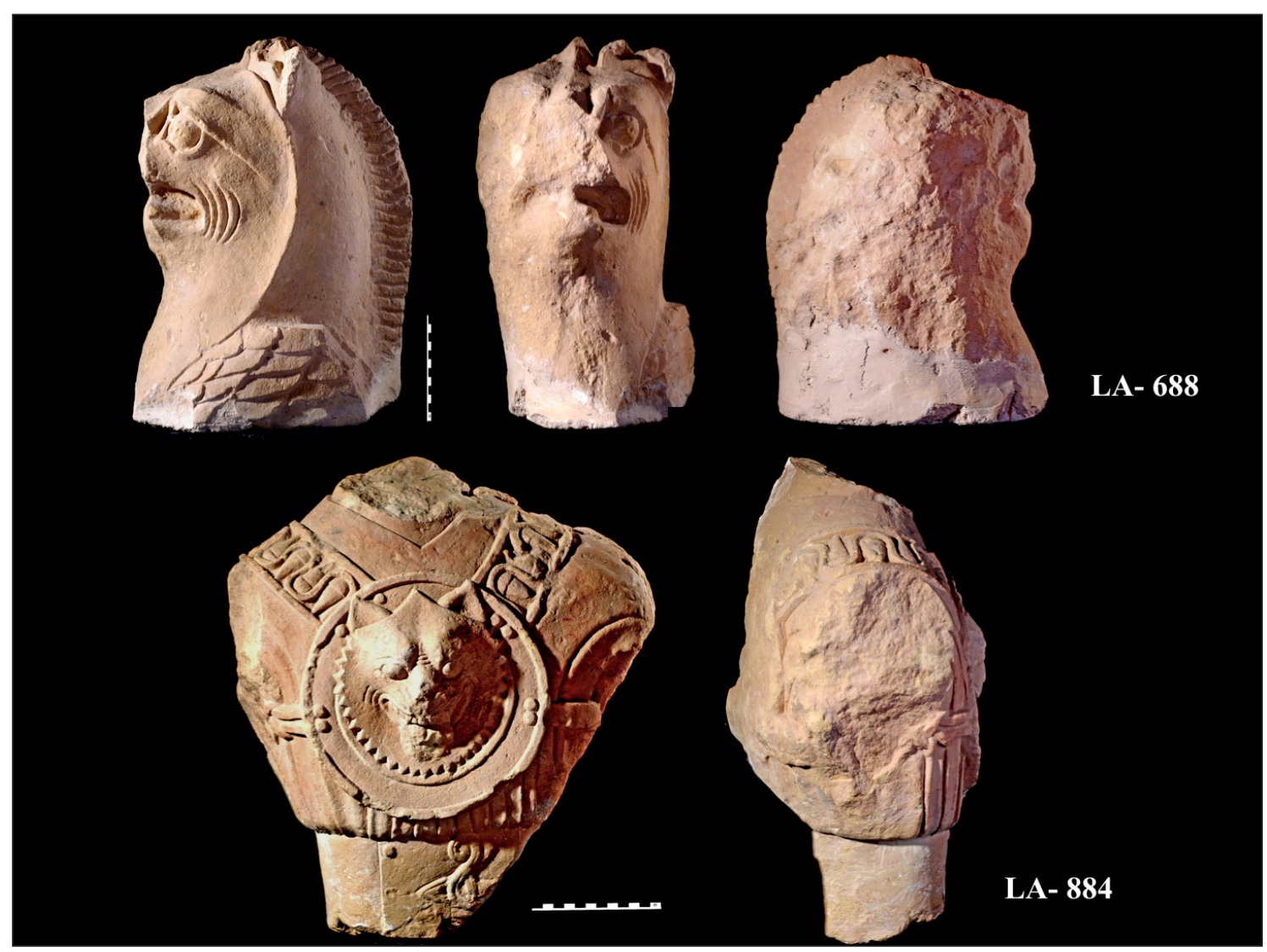

Figura 19. Esculturas ibéricas de grifo y el conocido "torso del guerrero" desde diferentes ángulos. Se encontraron reutilizadas como relleno de una "calle" construida en época augustea (Fundación L'Alcúdia).

En 1955, A. Ramos escribió sobre la estratigrafía en la que habían aparecido mayoritariamente las esculturas ibéricas en sus excavaciones. Se basó sobre todo en sus hallazgos de una supuesta "calle" al sur de la basílica que ha creado dudas entre los investigadores (Abad 2011: 350), pero que la revisión de los diarios de campo de Ramos Folqués nos ha permitido reconstruir más fidedignamente. Un total de 14 fragmentos escultóricos - la mayoría corresponden a los más emblemáticos del yacimiento, como el torso del guerrero (LA-884) o la cabeza de grifo (LA-688) - junto a algún otro arquitectónico (Ramos Folqués 1950: 353-357), le hicieron concluir su teoría a pie de excavación: "pienso si [...] al reedificar la ciudad, para nivelar el suelo, acabaran de destruir y esparcir los restos de la cultura anterior, y así lo parece demostrar el hecho de encontrar fragmentos escultóricos y arquitectónicos ibéricos, que sirven luego como materiales de construcción" (Ramos Folqués y Ronda 2018: f. 8r. diario ${ }^{\circ} 10$ de 1949), testimonio que explica la relación estratigráfica de las esculturas (Fig. 19).
Aquel descubrimiento de los fragmentos escultóricos en "la calle", supuso para Alejandro un gran éxito personal como arqueólogo, y en septiembre de 1955, repentinamente, decide trasladar las excavaciones "al Noroeste del lugar dónde fue hallada La Dama, y al Sur del lugar que excavó D. Antonio Vives Escudero en 1923". A. Ramos había visto la zanja del numismático - aquella que iba desde el punto mismo de la fita que Pedro Ibarra plantó, hacia el Oeste e interior de la loma-, de ahí que nunca dudó en ubicarla en su plano (Fig. 12.2). Creemos que Alejandro no quiso perder la oportunidad de excavar aquella otra zona para asegurarse la exploración de los dos puntos de la Dama: el que ya había sondeado en 1945 señalado por Campello Esclapez, y la zona (actual sector 10D), excavada antes por Eugène Albertini en $1905 \mathrm{y}$ por Vives en 1923, pues son abundantes las alusiones en sus cuadernos de campo: los vertederos tardíos los sitúa "hacia la Dama", o el linde de su "lugar 8" con la zanja de Vives. La coincidencia del lugar del hallazgo con sus excavaciones en el sector 10D puede reconocerse perfectamente en la fotografía del comienzo de 


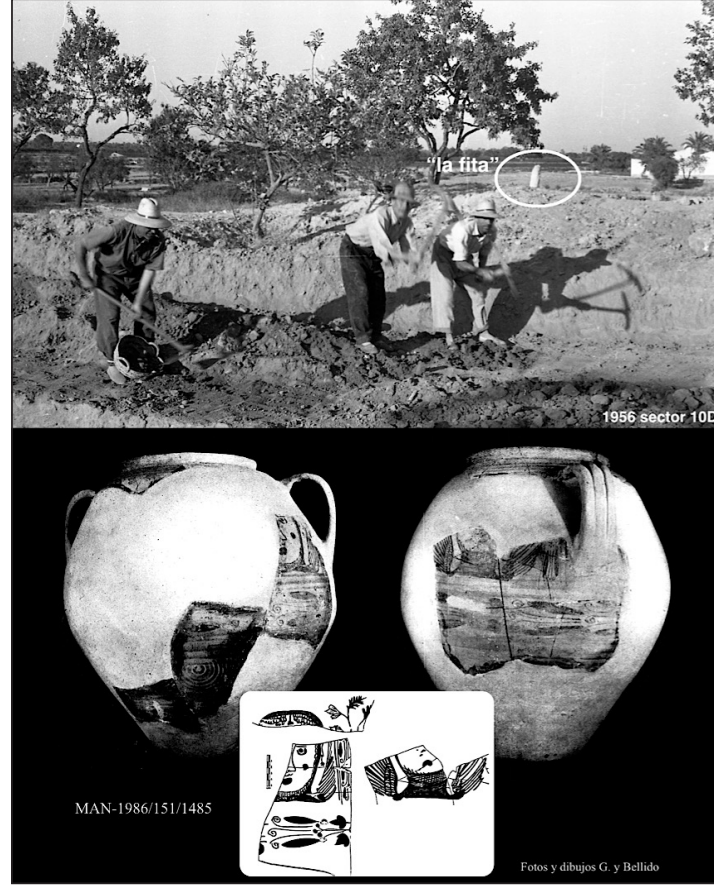

Figura 20. Inicio de la excavación de A. Ramos en 1956 (sector 10D) al lado de la "fita" (fotografía A. Ramos). Pithos de las diosas aladas cubiertas con velo y stephanos del MAN (fotografía y dibujo A. García y Bellido), pieza proveniente de las zanjas de Vives Escudero en la zona de la Dama en 1923, colindante con la excavación de 1956 de A. Ramos.

éstas en 1956 donde se observa junto a los obreros la columna que marcaba "la fita" de Ibarra (Fig. 20).

Alejandro Ramos adquirió su madurez como arqueólogo tras invertir cinco décadas en excavar $\mathrm{La}$ Alcudia, y sus estudios siempre tuvieron como objetivo el dar respuesta a los problemas estratigráficos del yacimiento, entre los cuales el contexto de la escultura ibérica fue un tema prioritario. Al final de sus días como profesional reflexionaba con el periodista Isidro Vidal sobre su trayectoria: "he disentido de García y Bellido, no estábamos de acuerdo en la cronología, pero luego el noventa y nueve por ciento de los arqueólogos se han pasado a mi bando, entre ellos Llobregat [...] Para mí, la excavación es la que revela la verdad en este sentido. Los estratos no mienten" (Diario Información 22 de abril de 1972).

En las excavaciones más recientes se han recuperado dos piezas escultóricas ibéricas contextualizadas. En 2011, en el estudio de un conjunto termal en la zona noroeste, salió una cabeza de sirena (LA-11.733) en el fondo de una fosa con material augusteo fechado entre el 30/10 a. n. e. (Tendero y Ronda 2014: 233234; fig. 6). En 2008 surgió formando parte de la base de la muralla occidental (Tendero 2017: 62; Ronda
2018: 173, fig. 205), como una piedra más, el faldellín de un guerrero mutilado (LA-6374), de igual modo que a Ramos Folqués le surgieron la mayoría de sus piezas en la "muralla púnica". Nuestra consideración es que, esos retazos de la base pétrea de lo que fue una muralla que encontró Ramos en la zona oriental (sector $6 \mathrm{~F}$ ), podrían correlacionarse con la muralla excavada de 2006 a 2008 en el perímetro occidental, pues son estos exiguos restos muy alterados los que quedan de la muralla hecha por los legionarios de la $2^{\mathrm{a}}$ fundación colonial en época de Augusto. Los indicios estratigráficos aportados por Ramos Folqués en sus diarios, revisados por nosotros, apuntan una cronología idéntica para el momento constructivo de su "calle" y la "muralla púnica", indicándonos que la escultura ibérica en La Alcudia suele aparecer en contextos secundarios, como mero ripio constructivo en una etapa de expansión urbanística de la ciudad en la que se recurrió a este material que debía hallarse disperso por el solar o sus aledaños (Ronda 2018: 348-350).

Con todo lo expuesto hasta el momento advertimos la importancia que el estudio de la estratigrafía ha supuesto para las lecturas en paralelo del hallazgo fortuito de la Dama. Asimismo, su estado de conservación indica que debió preservarse de un final destructivo y, quizás, el símil más aproximado a su contexto de aparición se encuentra en la leona de 1950, guarecida por un nicho de piedras que se situó en la base de la muralla en época de Augusto. Los motivos pudieron ser tal vez su connotación religiosa, su carácter de deidad, o tantas otras razones. "Los estratos no mienten", es el axioma que deducimos como único camino para el conocimiento, desde la arqueología, de esta obra universal.

\section{BIBLIOGRAFÍA}

Abad, L. 1997: "La Dama de Elche cumple cien años", Historia 16, agosto, http://hdl.handle. net/10045/60149

Abad, L. 2011: "La escultura ibérica de la Contestania. Entre lo divino y lo humano", J. Blánquez (ed.), ¿Hombres o dioses? Una nueva mirada a la escultura del mundo ibérico, Catálogo Museo Arqueológico Regional, Alcalá de Henares, 341-363.

Beltrán, A. 1993: "Algunas precisiones sobre la moneda ibérica", VV. AA., Homenaje a Alejandro Ramos Folqués. Ciclo de conferencias desarrollado en Elche entre los días 25 y 29 de noviembre de 1985, Elche, 57-63.

Blázquez, J. M. 1995: "La Dama de Elche, una obra maestra del arte ibérico", Historia 16 235, diciem- 
bre, 99-113. http://www.cervantesvirtual.com/nd/ ark:/59851/bmc0v8s8

Blázquez, J. M. 2004-2005: "Historiografía de la Dama de Elche. Sus prototipos de fuera de Hispania", Lucentum XXIII-XXIV, 61-88. https://doi. org/10.14198/lvcentvm2004-2005.23-24.04

Blázquez, J. M. 2006: "Cuatro razones por las que es indefendible la tesis de J.F. Moffitt sobre la modernidad de la Dama de Elche", http://www. cervantesvirtual.com/nd/ark:/59851/bmcj10f1

Blázquez, J. M. 2013: "La polémica sobre la autenticidad de la Dama de Elche", Real Academia de Cultura Valenciana. Aula de Humanidades y Ciencias, serie histórica 33. Temas del XXXII Curso de Historia y del V Curso de Ciencias. Valencia, 243-256.

Chapa, T. y González, J. 2013: "Las esculturas ibéricas del cerro de los santos en la exposición universal de Viena (1873)", Lucentum XXXII, 115-130. https://doi.org/10.14198/lvcentvm2013.32.05

Gagnaison, C., Montenat, C. y Rouillard, P. 2007: "L'environnement du site ibérique de La Alcudia et les carrières antiques de la Dame d'Elche (Province d'Alicante, Espagne)", ArcheoSciencies 31, 59-78. https://doi.org/10.4000/archeosciences.754

García y Bellido, A. 1943: La Dama de Elche y el conjunto de piezas arqueológicas reingresadas en España en 1941, Madrid.

García y Bellido, A. 1948: "Sobre la fecha romana del busto de Elche", Crónica del III Congreso Arqueológico del Sudeste Español Cartagena 1947, Murcia, 146-152.

García, F. y Gómez, M. V. 1997: "La Dama de Elche en la prensa española a lo largo de medio siglo", R. Olmos y T. Tortosa (eds.), La Dama de Elche. Lecturas desde la diversidad, Madrid, 222-237.

Gómez, M., Navarro J. V., Martín de Hijas, C., Del Egido, M., Algueró, M., González, E., Arteaga, A. y Juanes, D. 2008: "Revisión y actualización de los análisis de la policromía de la Dama de Baza. Comparación con la Dama de Elche", Bienes Culturales: Revista del Instituto del Patrimonio Histórico Español 8, 211-221.

Gómez, N. P. 1948: "Bibliografía. Reseña Ramos Folqués (A.).- La Dama de Elche. Madrid 1945", Anales del Centro de Cultura Valenciana IX, 66-ss.

Gutiérrez, S. 2016: "Memorias de una Dama. La Dama como lugar de memoria", El franquismo y la apropiación del pasado. El uso de la historia, de la arqueología y de la historia del arte para la legitimación de la dictadura, Madrid, 67-88.

Hübner, E. 1898: “Die Büste von Ilici”, Jahrbuch des Archaeologischen Instituts XIII, 114-ss.
Ibarra Ruiz. P. 1926: Elche, materiales para su historia, Cuenca.

Luxán, M. P., Prada, J. L., Dorrego, F. y Dorrego, J. F. 2011: "Human bone ashes found in the Dama de Elche (V-IV century B.C.) reveal its use as an ancient cinerary urn", Journal of Cultural Heritage XXX, https://doi.org/10.1016/j.culher.2010.12.006

Mélida, J. R. 1897: "Busto ante-romano descubierto en Elche", Boletín de la Real Academia de la Historia 31, 427-435.

Moffitt J. F. 1996: El caso de la Dama de Elche. Historia de una falsificación, Barcelona [traducción de Art Forgery: the case of the Lady of Elche, Gainesville, 1995].

Moffitt J. F. 2005: "La Dama de Elche tras diez años polémicos", Empiria, Revista de Metodología de ciencias sociales 10, julio-diciembre, 185-209. https://doi.org/10.5944/empiria.10.2005.1048

Moratalla, J., Rouillard, P. y Costa, L. 2014: "Las Canteras de Ferriol (Baix Vinalopó, Elche), un singular proyecto multidisciplinar de investigación histórica", MARQ. Arqueología y Museos, extra 01 Arqueología en Alicante en la primera década del siglo XXI, Alicante, 292-297.

Nicolini, G. 1974: "La Dame d'Elche, question d'authenticité", Bulletin de la Société Nationale des Antiquairies de France, 60-72. https://doi. org/10.3406/bsnaf.1976.8301

Nicolini, G. 1997: "La Dama de Elche. Historiografía y autenticidad", R. Olmos y T. Tortosa (eds.), $L a$ Dama de Elche. Lecturas desde la diversidad, Madrid, 107-121.

Olmos, R. 1997a: "Una Dama de todos", R. Olmos y T. Tortosa (eds.), La Dama de Elche. Lecturas desde la diversidad, Madrid, 17-47.

Olmos, R. 1997b: "La metamorfosis de un símbolo", 1897-1997 Cien años de una Dama, Catálogo de la Exposición, Madrid, 83-89.

Olmos, R. y Tortosa, T. 1996: "El caso de la Dama de Elche: más que una divergencia", Archivo Español de Arqueología 69, 219-226. https://doi. org/10.3989/aespa.1996.v69.240

Olmos, R. y Tortosa, T. 1997: "Aquel agosto de 1897...", R. Olmos y T. Tortosa (eds.), La Dama de Elche. Lecturas desde la diversidad, Madrid, 69-90.

Papí, C. 2005: "La venta de la Dama de Elche: desmontando algunas justificaciones", Recerques del Museo d'Alcoi 14, 157-168.

Paris, P. 1907: "Promenades archéologiques en Espagne: Elche", Bulletin Hispanique IX, octubrediciembre, 4, 317-334. https://doi.org/10.3406/ hispa.1907.1539

Paris, P. 1910: Promenades archéologiques en Espagne, Paris. 
Payá, J. [J. P. Valencianos] 1987: Historia de Elche contada sencillamente, Valencia.

Payá, J. 2007: La Dama d'Elig. Los investigadores opinan, Elche.

Ramos Fernández, R. 1997: "Recuerdos de la memoria", R. Olmos y T. Tortosa (eds.), La Dama de Elche. Lecturas desde la diversidad, Madrid, 75-90.

Ramos Fernández, R. 2003: Documentos y reflexiones sobre una Dama, Elche.

Ramos Fernández, R. 2011: "La Dama de Elche y los medios de comunicación", Simposio Internacional El patrimonio cultural como símbolo, Valladolid, 116-159.

Ramos Folqués, A. 1933: "Nuevos descubrimientos en Illici”, Archivo Español de Arte y Arqueología 26, 101-111.

Ramos Folqués, A. 1944: "La Dama de Elche. Nuevas aportaciones a su estudio", Archivo Español de Arqueología 56, 252-269.

Ramos Folqués, A. 1945: La Dama de Elche. Nuevas aportaciones a su estudio, Madrid.

Ramos Folqués, A. 1948: "La Dama de Elche. Datos para su cronología. El problema del nivel arqueológico de su hallazgo", Crónica del III Congreso Arqueológico del Sudeste Español Murcia 1947, Cartagena, 153-158.

Ramos Folqués, A. 1950: "Hallazgos escultóricos en La Alcudia de Elche", Archivo Español de Arqueología 23, 8, 353-359.

Ramos Folqués, A. 1955: Sobre escultura y cerámicas ilicitanas, Estudios Ibéricos 3, Valencia.

Ramos Folqués, A. y Ronda, A. 2018: Corpus documental. Diarios y memorias inéditas 1933-1971, Alicante, http://hdl.handle.net/10045/73867

Ramos Pérez, V. 1996: Vida de Gabriel Miró. Alicante, Alicante.

Rico De Estasen, J. 1947: "El hombre que descubrió la Dama de Elche", Revista Dígame, 19 de agosto.

Rico De Estasen, J. 1948: "En ocasión del IV Congreso Arqueológico del Sudeste de España. Descubrimientos Arqueológicos en Elche", Diario de Barcelona 119, 19 de mayo-

Rico De Estasen, J. 1962: “Un pasaje inédito de la historia de la Dama de Elche. Contado por la inolvidable hija de Gabriel Miró", Revista Dígame, 14 de agosto.
Rodero, A. y Rovira, S. 1997: "Las posibilidades de análisis de una pieza singular", R. Olmos y T. Tortosa (eds.), La Dama de Elche. Lecturas desde la diversidad, Madrid, 158-162.

Rodríguez-Tajuelo, M. E. (2016): La percepción social de la arqueología en España a través de los medios de comunicación: los descubrimientos en la prensa escrita hasta 1925, T. I, Madrid. http:// hdl.handle.net/10486/671921.

Ronda, A. M. 2016: L'Alcúdia de Alejandro Ramos Folqués 50 años de estudios arqueológicos, Tesis de la Universidad de Alicante, Alicante.

Ronda, A. M. 2018: L'Alcúdia de Alejandro Ramos Folqués. Contextos arqueológicos y humanos en el yacimiento de la Dama de Elche, Anejos de Lucentum 24, Alicante.

Tendero, M. 2016: "Ilici (L'Alcúdia d'Elx)", La rella 28, Anuari de L'Institut d'Estudis del Baix Vinalopó, 111-142.

Tendero, M. 2017: "Ilici, una ciudad en la vía (L'Alcúdia d'Elx)", Vías de comunicación y espacios de defensa y de frontera en las costas del sudeste de la Península Ibérica. Una visión desde el mundo antiguo y medieval, Rojales, 51-75.

Tendero, M. y Ronda, A. M. 2014: "Ilici. I. La ciudad romana de Ilici", M. H. Olcina (ed.), Ciudades romanas valencianas. Actas de las jornadas, Alicante, 226-242.

Tortosa, T. 1996: "Algunos apuntes sobre los personajes y los textos en la historia de la Dama de Elche”, Revista de Estudios Ibéricos 2, 213-230.

Verdú, C. 2011: "La colección de Pedro Ibarra en el Archivo Histórico Municipal de Elche", Quintas Jornadas de Archivo y Memoria. Extraordinarios y fuera de serie: formación, conservación y gestión de archivos personales, Madrid. http://www. archivoymemoria.com [Consulta: 01/03/2011].

Villarías-Robles, J. J. R., Olmos, R., Lavado, P., Delaunay, J. M., Ramírez, J. A. y Bustamante, J. 1997: "Debate. La Dama ¿una falsificación del siglo XIX?", R. Olmos y T. Tortosa (eds.), La Dama de Elche. Lecturas desde la diversidad, Madrid, 239-248.

Recibido: 26-10-2017

Aceptado: 04-04-2018 